\title{
Practical Evaluation of Resistance of High-Speed Catamaran Hull Forms-Part I
}

\author{
Prasanta K Sahoo, Australian Maritime College, Launceston, Australia \\ Marcos Salas, University of Austral, Chile \\ Adam Schwetz, Schwetz Design, Australia
}

\begin{abstract}
Although catamaran configuration has been around for a longtime, it is only in the recent past that such hull forms have seen unprecedented growth in the high-speed ferry industry. One of the design challenges faced by naval architects is accurate prediction of the hydrodynamic characteristics of such vessels primarily in the areas of resistance, propulsion and seakeeping. Even though considerable amount of research has been carried out in this area, there remains a degree of uncertainty in the prediction of calm water resistance of catamaran hull forms. This paper attempts to present the research work carried out so far and what needs to be undertaken in future for a reasonably accurate prediction of catamaran resistance characteristics.

The authors have examined the deep water wave resistance characteristics of a series of transom stern, semi-displacement slender catamaran hull forms of round bilge as well as single chine hull forms, which are of utmost importance to the high-speed ferry industry.

The accuracy of the established regression equation has been seen to deviate appreciably by various sources of uncertainties. Verification of the equation with experimental database is also lacking to a certain extent. Further research is therefore needed to refine the accuracy as well as to complete the selection of crucial parameters employed. However, the results obtained have shown considerable promise, and a regression equation for predicting wave resistance of catamarans in calm water can be seen as achievable.
\end{abstract}

\section{KEYWORDS}

Catamaran, Resistance, Wave Resistance, CFD

\section{INTRODUCTION}

Catamarans account for $43 \%$ of the fleet by vessel numbers as given by the report of Drewry Shipping Consultants (1997). Slender hull forms and higher speed capabilities provoked the need of technological evolution in predicting their preliminary characteristics of resistance. Calm water resistance of catamarans is in general attributed to two major components namely, viscous resistance and calm water wave resistance. The former has been acceptably determined from ITTC-1957 line using a form factor component whilst the latter still remains to be a stimulating question to the researchers. It is understood that the solutions cannot be generalized by one simple formula but varied in accordance with specific configurations of catamarans.

With the advent of Computational Fluid Dynamics (CFD), there is hope for further development. In this paper a computational package, SHIPFLOW, is used to generate data of wave making resistance of catamaran hull forms, and the regression equations were developed based on the data. In the end credibility of these equations have been compared with several other theoretical and experimental methods presently available. This paper concentrates on both single hard-chine as well as round bilge hull forms with transom stern. The model parameters have been based on data of modern catamarans found from the literature survey and on the suggestions given by Doctors et al. (1996).

\section{Prediction Of Total Resistance - BaCkground}

The background of the work has been based on some of the important modern methods in application so far. These methods have been briefly explained below.

\section{INSEL \& MOLLAND'S METHOD (1992)}

The paper by Insel and Molland (1992) summarizes a calm water resistance investigation into highspeed semi-displacement catamarans, with symmetrical hull forms based on experimental work carried 
out at the University of Southampton.

Two interference effects contributing to the total resistance effect were established, being viscous interference, caused by asymmetric flow around the demihulls which effects the boundary layer formation, and wave interference, due to the interaction of the wave systems produced by each demihull. Particulars of models tested by Insel and Molland (1992) are presented in Table 1. The particulars of the models used in the investigation are presented in Table 2.

Table 1: Catamaran Geometric Parameters [Insel and Molland (1992)]

\begin{tabular}{|c|c|c|c|c|}
\hline Geometric Parameters & $\mathrm{L} / \nabla^{1 / 3}$ & $\mathrm{~L} / \mathrm{B}$ & $\mathrm{B} / \mathrm{T}$ & $\mathrm{C}_{\mathrm{B}}$ \\
\hline Range of Application & 6 to 9 & 6 to 12 & 1 to 3 & 0.33 to 0.45 \\
\hline
\end{tabular}

Table 2: Model Particulars [ Insel and Molland (1992)]

\begin{tabular}{|c|c|c|c|c|c|}
\hline Models & $\mathrm{L} / \nabla^{1 / 3}$ & $\mathrm{~L} / \mathrm{B}$ & $\mathrm{B} / \mathrm{T}$ & $\mathrm{C}_{\mathrm{B}}$ & $\mathrm{LCB} / \mathrm{L}$ from transom \\
\hline $\mathrm{C} 2$ & 7.1 & 10 & 1.6 & 0.44 & $50 \%$ \\
\hline $\mathrm{C} 3$ & 6.3 & 7 & 2 & 0.397 & $43.6 \%$ \\
\hline $\mathrm{C} 4$ & 7.4 & 9 & 2 & 0.397 & $43.6 \%$ \\
\hline $\mathrm{C} 5$ & 8.5 & 11 & 2 & 0.397 & $43.6 \%$ \\
\hline
\end{tabular}

Models C3, C4 and C5 were of round bilge hull form derived from the NPL series and model C2 was of the parabolic Wigley hull form. Body plans of these models are shown in Figures 1. All models were tested over a range of Froude numbers of 0.1 to 1.0 in the demi-hull configuration and catamaran configuration with separation ratios, $\mathrm{s} / \mathrm{L}$, of $0.2,0.3,0.4$ and 0.5 . Calm water resistance, running trim, sinkage and wave pattern analysis experiments were carried out.
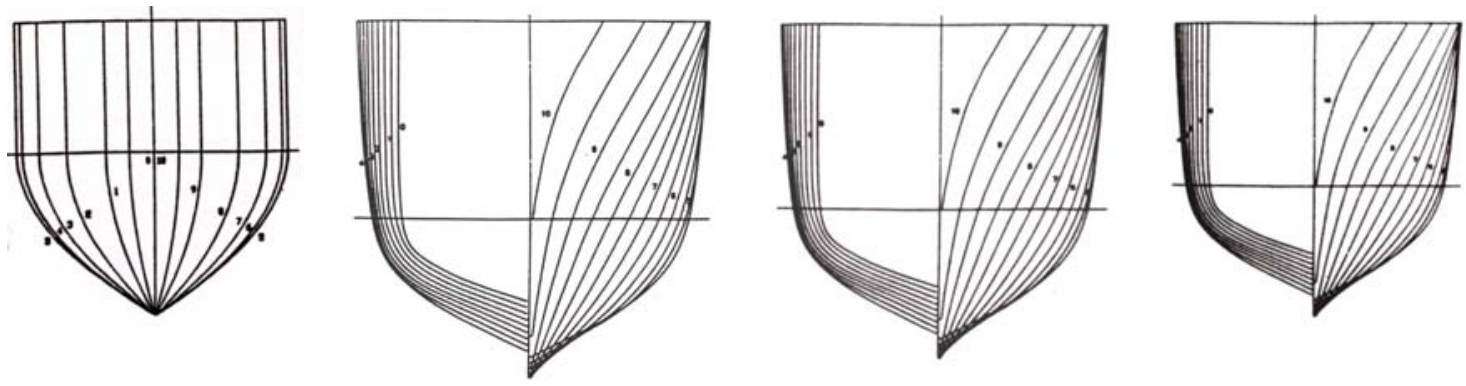

Figure 1: Body-plan of Models C2, C3, C4 and C5 [Insel and Molland (1992)]

The authors proposed that the total resistance of a catamaran should be expressed by equation (1):

$$
C_{T C A T}=(1+\phi k) \sigma C_{F}+\tau C_{w}
$$

$\phi$ has been introduced to take account of pressure field change around the demi-hull and $\sigma$ takes account of the velocity augmentation between the hulls and would be calculated from an integration of local frictional resistance over the wetted surface and $(1+k)$ is the form factor for the demi-hull in isolation. For practical purposes, $\phi$ and $\sigma$ can be combined into a viscous interference factor $\gamma$ where $(1+\phi k) \sigma=(1+\not k)$ whence:

$$
C_{T C A T}=(1+\not k) C_{F}+\tau C_{W}
$$

noting that for demi-hull in isolation, $\gamma=1$ and $\tau=1$, and for a catamaran, $\tau$ can be calculated from equation (3).

$$
\tau=\frac{C_{W C A T}}{C_{W \text { DEMI }}}=\frac{\left[C_{T}-(1+\not k) C_{F}\right]_{C A T}}{\left[C_{T}-(1+k) C_{F}\right]_{D E M I}}
$$

The authors conclude that the form factor, for practical purposes, is independent of speed and should thus be kept constant over the speed range. This was a good practical solution to a complex engineering problem at that point in time. The derived form factors for the mono-hull configuration are shown in Table 3. The authors also conclude that the viscous interference factor $\gamma$ is effectively independent of 
speed and should be kept constant across the speed range and it depends primarily on L/B ratio.

Table 3: Derived form factors [Insel and Molland (1992)]

\begin{tabular}{|c|c|c|c|c|}
\hline Mono-hull & C2 & C3 & C4 & C5 \\
\hline$(1+\mathrm{k})$ & 1.10 & 1.45 & 1.30 & 1.17 \\
\hline
\end{tabular}

The authors further conclude that:

- The vessels tested have an appreciable viscous form effect, and are higher for catamarans where viscous interference takes place between the hulls.

- Viscous resistance interference was found to be independent of speed and hull separation, and rather is dependent on demi-hull length to beam ratio.

- Generally higher hull separation ratios result in smaller wave interference, with beneficial wave interference between Froude numbers of 0.35 to 0.42 .

- Catamarans display higher trim angles than mono-hulls, and that the trim angle is reduced with increasing hull separation ratios.

- A ship to model correlation exercise is required for the extrapolation techniques presented to be validated.

\section{MILLWARD's METHOD (1992)}

In his investigation, Millward (1992) has reported his test results on a series of catamarans characterised by hull length-beam ratio $(L / B)$ of 10 and a beam-draft ratio $(B / T)$ of 2 . Millward (1992) in fact intended to adhere to the common parameter range as suggested by Insel and Molland (1992). Figure 2 reproduced from the article demonstrates the effect of separation ratio on resistance.

He introduced a new wave resistance coefficient,

$$
C_{W}^{*}=\frac{R^{*}}{F n^{2}}
$$

in which, $R^{*}=\frac{R_{W}}{\frac{8}{\pi} \rho g \frac{B^{2} T^{2}}{L}}$ and $R_{W}$ is the wave resistance.

The frictional resistance is calculated using ITTC 1957 line. From this, the total resistance $\left(R_{T}\right)$ of catamaran can be found by:

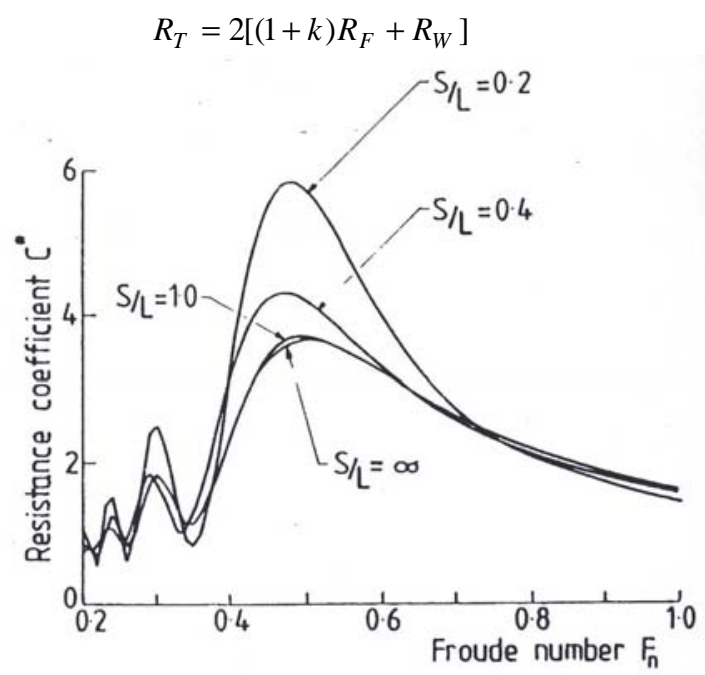

Figure 2: Effect of Hull Separation on Catamaran Resistance [Millward(1992)]

\section{MOLLAND ET AL. METHOD (1994)}

The paper by Molland et al. (1994) is an extension of the work conducted by Insel and Molland (1992). Additional models are tested with the particulars listed in Tables 4. The research and results are also detailed in the University of Southampton Ship Science Report 71, (1994). Form factors as per Molland et al. (1994) are shown in Table 5. In addition to this, Molland et al. (1994) gives the experimental data 
of a systematic series of high-speed displacement catamaran forms in which the viscous form factors are shown as in Table 6. For further details on the resistance data readers are referred to the above report.

Table 4: Particulars of Models [Molland et al (1994)]

\begin{tabular}{|c|c|c|c|c|c|c|c|c|c|c|}
\hline Models & $\mathbf{3 b}$ & $\mathbf{4 a}$ & $\mathbf{4 b}$ & $\mathbf{4 c}$ & $\mathbf{5 a}$ & $\mathbf{5 b}$ & $\mathbf{5 c}$ & $\mathbf{6 a}$ & $\mathbf{6 b}$ & $\mathbf{6 c}$ \\
\hline $\mathbf{L} / \mathbf{B}$ & 7.0 & 10.4 & 9.0 & 8.0 & 12.8 & 11.0 & 9.9 & 15.1 & 13.1 & 11.7 \\
\hline $\mathbf{L} / \boldsymbol{\nabla}^{\mathbf{1 / 3}}$ & 6.27 & 7.40 & 7.41 & 7.39 & 8.51 & 8.50 & 8.49 & 9.50 & 9.50 & 9.50 \\
\hline $\mathbf{B} / \mathbf{T}$ & 2.0 & 1.5 & 2.0 & 2.5 & 1.5 & 2.0 & 2.5 & 1.5 & 2.0 & 2.5 \\
\hline $\mathbf{C}_{\mathbf{B}}$ & 0.397 & 0.397 & 0.397 & 0.397 & 0.397 & 0.397 & 0.397 & 0.397 & 0.397 & 0.397 \\
\hline $\mathbf{L C B} / \mathbf{L} \mathbf{( \% )}$ & 43.6 & 43.6 & 43.6 & 43.6 & 43.6 & 43.6 & 43.6 & 43.6 & 43.6 & 43.6 \\
\hline
\end{tabular}

Table 5: Model Form Factors [Molland et al (1994)]

\begin{tabular}{|c|c|c|c|c|c|c|c|c|c|}
\hline Model & Monohull & \multicolumn{2}{|c|}{$\mathbf{s} / \mathbf{L}=\mathbf{0 . 2}$} & \multicolumn{2}{|c|}{$\mathbf{s} / \mathbf{L}=\mathbf{0 . 3}$} & \multicolumn{2}{c|}{$\mathbf{s} / \mathbf{L}=\mathbf{0 . 4}$} & \multicolumn{2}{c|}{$\mathbf{s} / \mathbf{L}=\mathbf{0 . 5}$} \\
\hline Form factors & $\mathbf{( 1 + k )}$ & $\mathbf{1 + \gamma k}$ & $\boldsymbol{\gamma}$ & $\mathbf{1 + \gamma k}$ & $\boldsymbol{\gamma}$ & $\mathbf{1 + \gamma k}$ & $\boldsymbol{\gamma}$ & $\mathbf{1 + \gamma} \mathbf{\gamma}$ & $\boldsymbol{\gamma}$ \\
\hline $\mathbf{3 b}$ & 1.45 & 1.6 & 1.33 & 1.65 & 1.44 & 1.55 & 1.2 & 1.60 & 1.3 \\
\hline $\mathbf{4 a}$ & 1.30 & 1.43 & 1.43 & 1.43 & 1.43 & 1.46 & 1.5 & 1.44 & 1.5 \\
\hline $\mathbf{4 b}$ & 1.30 & 1.47 & 1.57 & 1.43 & 1.43 & 1.45 & 1.5 & 1.45 & 1.5 \\
\hline $\mathbf{4 c}$ & 1.30 & 1.41 & 1.37 & 1.39 & 1.30 & 1.48 & 1.6 & 1.44 & 1.5 \\
\hline $\mathbf{5 a}$ & 1.28 & 1.44 & 1.57 & 1.43 & 1.54 & 1.44 & 1.6 & 1.47 & 1.7 \\
\hline $\mathbf{5 b}$ & 1.26 & 1.41 & 1.58 & 1.45 & 1.73 & 1.40 & 1.5 & 1.38 & 1.5 \\
\hline $\mathbf{5 c}$ & 1.26 & 1.41 & 1.58 & 1.43 & 1.65 & 1.42 & 1.6 & 1.44 & 1.7 \\
\hline $\mathbf{6 a}$ & 1.22 & 1.48 & 2.18 & 1.44 & 2.0 & 1.46 & 2.1 & 1.48 & 2.2 \\
\hline $\mathbf{6 b}$ & 1.22 & 1.42 & 1.91 & 1.40 & 1.82 & 1.47 & 2.1 & 1.44 & 2.0 \\
\hline $\mathbf{6 c}$ & 1.23 & 1.40 & 1.74 & 1.40 & 1.74 & 1.45 & 2.0 & 1.44 & 1.9 \\
\hline
\end{tabular}

Table 6: Viscous Form Factors of Catamarans [(Molland et al. 1994)]

\begin{tabular}{|c|c|c|c|c|c|}
\hline & & $\mathbf{s} / \mathbf{L}=\mathbf{0 . 2}$ & $\mathbf{s} / \mathbf{L}=\mathbf{0 . 3}$ & $\mathbf{s} / \mathbf{L}=\mathbf{0 . 4}$ & $\mathbf{s} / \mathbf{L}=\mathbf{0 . 5}$ \\
\hline $\mathbf{L} / \boldsymbol{\nabla}^{\mathbf{1 / 3}}$ & $\mathbf{B} / \mathbf{T}$ & $\mathbf{1}+\boldsymbol{\gamma k}$ & $\mathbf{1}+\boldsymbol{\gamma k}$ & $\mathbf{1 + \gamma k}$ & $\mathbf{1 + \gamma k}$ \\
\hline 8.5 & 1.5 & 1.44 & 1.43 & 1.44 & 1.47 \\
\hline 8.5 & 2.0 & 1.41 & 1.45 & 1.4 & 1.38 \\
\hline 8.5 & 2.5 & 1.41 & 1.43 & 1.42 & 1.44 \\
\hline Average & & $\mathbf{1 . 4 2}$ & $\mathbf{1 . 4 4}$ & $\mathbf{1 . 4 2}$ & $\mathbf{1 . 4 3}$ \\
\hline 9.5 & 1.5 & 1.48 & 1.44 & 1.46 & 1.48 \\
\hline 9.5 & 2.0 & 1.42 & 1.40 & 1.47 & 1.44 \\
\hline 9.5 & 2.5 & 1.40 & 1.40 & 1.45 & 1.44 \\
\hline Average & & $\mathbf{1 . 4 3}$ & $\mathbf{1 . 4 1}$ & $\mathbf{1 . 4 6}$ & $\mathbf{1 . 4 5}$ \\
\hline
\end{tabular}

Armstrong's thesis entitled "A Thesis on the Viscous Resistance and Form Factor of High-speed Catamaran Ferry Hull Forms", [Armstrong (2000)], examines the current methods for predicting the resistance of recently designed high-speed catamarans. Current literature suggests large form factors are needed for correlation between model scale and full scale, which Armstrong (2000) claims, contradicts the expectation that long slender hull forms would have low values. Armstrong proposals on form factors are presented in Appendix I.

\section{FORM FACTOR OF CATAMARANS}

As there is no equation giving the form factor of catamarans $(1+\gamma \mathrm{k})$ directly from their particulars, a regression model had to be developed from the data of Table 6. For each Froude number studied, the catamaran form factor $(1+\gamma \mathrm{k})$ will be a function of the different geometrical particulars and the monohull form factor $(1+\mathrm{k})$ of the hull forms. Using multiple regression analysis, a general equation 
has been found as shown in equation (7) and regression coefficients shown in Table 7.

$$
\begin{aligned}
& (1+\gamma k)=f\left(\frac{B}{T} ; \frac{L}{\nabla^{1 / 3}} ; \frac{s}{L} ;(1+k)\right) \\
& (1+\gamma k)=a_{0}+a_{1} \frac{B}{T}+a_{2} \frac{L}{\nabla^{1 / 3}}+a_{3} \frac{s}{L}+a_{4}(1+k)+a_{5} \frac{B}{T} \frac{L}{\nabla^{1 / 3}}+a_{6} \frac{B}{T} \frac{s}{L}+a_{7} \frac{L}{\nabla^{1 / 3}} \frac{s}{L}+a_{8} \frac{B}{T}(1+k) \\
& +a_{9} \frac{L}{\nabla^{1 / 3}}(1+k)+a_{10} \frac{s}{L}(1+k)+a_{11} \frac{B}{T} \frac{L}{\nabla^{1 / 3}} \frac{s}{L}+a_{12} \frac{B}{T} \frac{L}{\nabla^{1 / 3}}(1+k)+a_{13} \frac{B}{T} \frac{s}{L}(1+k)+a_{14} \frac{L}{\nabla^{1 / 3}} \frac{s}{L}(1+k)
\end{aligned}
$$

Table 7: Regression Coefficients for Equation 7

\begin{tabular}{|c|c|c|c|}
\hline$a_{0}$ & 0 & $a_{8}$ & -2.506 \\
\hline$a_{1}$ & 0.258 & $a_{9}$ & -2.432 \\
\hline$a_{2}$ & 2.505 & $a_{10}$ & 100.173 \\
\hline$a_{3}$ & -150.791 & $a_{11}$ & -1.636 \\
\hline$a_{4}$ & 4.932 & $a_{12}$ & 1.417 \\
\hline$a_{5}$ & -1.446 & $a_{13}$ & -43.355 \\
\hline$a_{6}$ & 68.628 & $a_{14}$ & -2.927 \\
\hline$a_{7}$ & 6.549 & & \\
\hline
\end{tabular}

\section{REgRESSION FOLLOWING MOLLAND ET AL. (1994) METHOD}

Basing on the NPL data of the studies conducted by Molland et al. (1994), a speed independent regression equation has been developed so as to obtain the wave resistance coefficient directly from the particulars of the catamaran.

The $C_{W C A T}$ is given by the equation (8) and regression coefficients as shown in Table 8.

$$
\begin{aligned}
& C_{W C A T}=b_{0}+b_{1} \frac{L}{B}+a_{2} \frac{B}{T}+b_{3} \frac{L}{\nabla^{1 / 3}}+b_{4} \frac{s}{L}+b_{5} \frac{L}{B} \frac{B}{T}+b_{6} \frac{L}{B} \frac{L}{\nabla^{1 / 3}}+b_{7} \frac{B}{T} \frac{L}{\nabla^{1 / 3}}+b_{8} \frac{L}{B} \frac{s}{L}+b_{9} \frac{B}{T} \frac{s}{L} \\
& +b_{10} \frac{L}{\nabla^{1 / 3}} \frac{s}{L}+b_{11} \frac{L}{B} \frac{B}{T} \frac{L}{\nabla^{1 / 3}}+b_{12} \frac{L}{B} \frac{B}{T} \frac{s}{L}+b_{13} \frac{L}{B} \frac{L}{\nabla^{1 / 3}} \frac{s}{L}+b_{14} \frac{B}{T} \frac{L}{\nabla^{1 / 3}} \frac{s}{L}+b_{15} \frac{L}{B} \frac{B}{T} \frac{L}{\nabla^{1 / 3}} \frac{s}{L}
\end{aligned}
$$

\begin{tabular}{|c|c|c|c|c|c|c|c|c|c|c|c|c|c|c|c|c|}
\hline Fn & $b_{0}$ & $b_{1}$ & $b_{2}$ & $b_{3}$ & $b_{4}$ & $b_{5}$ & $b_{6}$ & $b_{7}$ & $b_{8}$ & $b_{9}$ & $b_{10}$ & $b_{11}$ & $b_{12}$ & $b_{13}$ & $b_{14}$ & $b_{15}$ \\
\hline 0.20 & 0 & -1.010 & -3.482 & 2.936 & 0.434 & -1.782 & 0.053 & 1.169 & 2.437 & 8.242 & -6.962 & 0.041 & 4.230 & -0.137 & -2.816 & -0.092 \\
\hline 0.25 & 0 & -0.624 & -1.430 & 0.911 & 14.494 & -0.576 & 0.063 & 0.573 & 1.051 & -3.927 & -3.763 & -0.004 & 0.905 & -0.043 & 0.120 & -0.021 \\
\hline 0.30 & 0 & -0.135 & -1.171 & 0.928 & -21.610 & -0.730 & 0.012 & 0.487 & 3.235 & 12.628 & 0.754 & 0.017 & -0.351 & -0.328 & -1.728 & 0.119 \\
\hline 0.35 & 0 & -1.870 & -8.177 & 5.059 & 4.144 & -2.346 & 0.095 & 2.106 & 4.918 & 21.604 & -12.503 & 0.012 & 5.082 & -0.270 & -5.153 & 0.021 \\
\hline 0.40 & 0 & -1.437 & -2.620 & 2.150 & 32.489 & -0.306 & 0.082 & 0.413 & 2.854 & -2.519 & -11.615 & -0.022 & 2.830 & -0.035 & -0.280 & -0.075 \\
\hline 0.45 & 0 & 2.504 & 10.900 & -6.979 & 10.979 & 4.132 & -0.114 & -2.901 & -0.970 & -7.798 & 10.730 & -0.100 & -11.150 & -0.046 & 5.288 & 0.444 \\
\hline 0.50 & 0 & 5.921 & 19.565 & -8.431 & 39.226 & 1.270 & -0.324 & -2.430 & -11.378 & -24.067 & 13.500 & 0.076 & -6.242 & 0.614 & 3.816 & 0.171 \\
\hline 0.55 & 0 & 3.149 & 26.826 & -2.589 & 111.705 & -1.619 & -0.237 & -2.989 & -13.638 & -77.986 & -5.439 & 0.244 & 3.388 & 1.254 & 9.134 & -0.586 \\
\hline 0.60 & 0 & 1.398 & 29.096 & 0.614 & 107.296 & -2.655 & -0.191 & -3.503 & -9.326 & -83.327 & -13.326 & 0.320 & 6.584 & 1.134 & 10.051 & -0.797 \\
\hline 0.65 & 0 & 0.701 & 17.120 & -0.514 & 65.457 & -0.368 & -0.092 & -2.409 & -4.015 & -38.325 & -7.119 & 0.120 & 0.620 & 0.512 & 5.253 & -0.199 \\
\hline 0.70 & 0 & 1.602 & 13.789 & -2.218 & 59.031 & 0.291 & -0.122 & -2.024 & -5.949 & -33.130 & -2.283 & 0.079 & -0.876 & 0.572 & 4.822 & -0.136 \\
\hline 0.75 & 0 & 2.173 & 9.941 & -2.585 & 53.376 & 0.192 & -0.151 & -1.356 & -7.233 & -26.712 & -1.242 & 0.067 & 0.184 & 0.637 & 3.380 & -0.169 \\
\hline 0.80 & 0 & 1.811 & 9.833 & -2.216 & 44.561 & 0.217 & -0.139 & -1.497 & -6.278 & -27.259 & -1.141 & 0.074 & 0.618 & 0.591 & 3.702 & -0.230 \\
\hline 0.85 & 0 & 1.841 & 10.540 & -1.971 & 38.833 & -0.315 & -0.138 & -1.409 & -5.976 & -28.430 & -1.758 & 0.106 & 2.476 & 0.556 & 3.214 & -0.330 \\
\hline 0.90 & 0 & 2.148 & 13.265 & -2.749 & 33.474 & 0.104 & -0.168 & -2.080 & -5.934 & -32.675 & 0.171 & 0.120 & 1.401 & 0.559 & 4.515 & -0.338 \\
\hline 0.95 & 0 & 2.448 & 13.923 & -3.472 & 31.412 & 0.402 & -0.183 & -2.266 & -6.845 & -36.448 & 3.349 & 0.117 & -0.169 & 0.599 & 5.638 & -0.315 \\
\hline 1.00 & 0 & 2.882 & 14.586 & -4.781 & 7.184 & 0.961 & -0.189 & -2.480 & -5.623 & -27.406 & 9.518 & 0.100 & -2.972 & 0.363 & 5.129 & -0.140 \\
\hline
\end{tabular}

Table 8: Regression Coefficients for Equation 8 


\section{VWS HARd CHINE '89 SERIES REgRESSION METHOdOLOGY (1995)}

This method was proposed by Zips (1995) using multiple regression analysis of test data intended to predict the resistance of hard chine catamarans with hull parameters in the scope of the VWS Hard Chine Catamaran Hull Series '89. This series is valid for the ranges shown in Table 9.

The total resistance is given by:

$$
R_{T}=\left[R_{F}+\left(\varepsilon_{R} \times \nabla \times \rho \times g\right)\right]
$$

The details of this methodology are illustrated in Appendix II.

Table 9: Parameter Range [Zips (1995)]

\begin{tabular}{|l|l|}
\hline Parameter & Range \\
\hline Length & 20 to $80 \mathrm{~m}$ \\
\hline Displacement & 25 to 1000 tonnes \\
\hline Fn & 0.8 to 1.4 \\
\hline Length-Beam ratio of demihull $\mathrm{L}_{\mathrm{WL}} / \mathrm{B}_{\mathrm{XDH}}$ & 7.55 to 13.55 \\
\hline Deadrise amidships $\beta_{M}$ & $16^{\circ}$ to $38^{\circ}$ \\
\hline Transom Wedge $\delta_{W}$ & $0^{\circ}$ to $12^{\circ}$ \\
\hline
\end{tabular}

\section{HANHIROVA, RINTALA AND KARPPINEN METHOD (1995)}

The authors have proposed a prediction method of estimating the resistance of high-speed mono- and multihull vessels based on Michell's integral along with a regression correction. The regression method is based on the resistance predicted by Michell's integral and model experiments carried out on 30 different hull shapes, several of which were catamarans and trimarans. Significant aspect of this method is that it can be applied to both mono- and multihull vessels in the preliminary design stage. It may be noted that the regression coefficients correction to $\mathrm{C}_{\mathrm{W}}$ have not been published. Regression correction was carried out as follows:

$$
\begin{aligned}
& C_{T}=C_{F}+C_{R}+C_{A} \\
& C_{F}=\frac{0.075}{\left(\log _{10} R_{n}-2\right)^{2}} \\
& C_{A}=0
\end{aligned}
$$

The experimental residual coefficient was given by:

$$
C_{R}=C_{T}-C_{F}
$$

which was used to calculate the required correction to wave resistance coefficient $\mathrm{C}_{\mathrm{W}}$ as predicted by Michell's integral. The required correction to wave resistance coefficient was given by:

$$
\Delta C_{W}=C_{R}-C_{W}
$$

The required regression equations for $\Delta \mathrm{C}_{\mathrm{W}}$ have been reproduced in Appendix III.

\section{Single Chine Series Regression of Pham, Kantimahanthi And SaHoo (2001)}

A systematic series of 18 hard-chine demi-hulls were generated, and their wave resistance in calm water determined using SHIPFLOW. The recorded data were then statistically analysed to determine an accurate regression equation. The achieved regression equation has been compared with three empirical methods that have commonly been used so far. The accuracy of the established regression equation has been seen to deviate appreciably by various sources of uncertainties. Verification of the equation with experimental database is also lacking. Further research is therefore needed to refine the accuracy as well as to complete the selection of crucial parameters employed. However, the results obtained have shown considerable promise, and a regression equation for predicting wave resistance of 
single chine catamaran hull forms in calm water can be seen as achievable.

The result of the literature survey on 50 contemporary catamaran configurations when integrated with the results shown by Doctor's et al. (1994) have led to the parameters shown in Table 10 (Appendix IV). A parent hull form was developed with $\mathrm{C}_{\mathrm{B}}=0.55, \mathrm{~L} / \mathrm{B}=15.6$ and $\mathrm{B} / \mathrm{T}=2.0$. Basing on this hull form, a total of 18 models were developed (total including the parent hull form). The details of the models are shown in the table above. Only the demi-hulls were considered during hull form generation, which were later extended to twin hulls, with demi-hulls being symmetrical with respect to each other and with respect to their individual centre-line planes.

With $C_{W C A T}$ as the dependent variable, and the target vessel type being catamaran where s/L could be a significant parameter, the equation shown has been assumed for wave resistance coefficient along with the regression coefficients shown in Table 11. The body plans of demi-hulls have been shown in Appendix IV.

$$
C_{W C A T}=\alpha(L / B)^{\beta_{1}}(B / T)^{\beta_{2}} C_{B} \beta_{3}(s / L)^{\beta_{4}}
$$

Table 10: Model Particulars [Pham, Kantimahanthi and Sahoo (2001)]

\begin{tabular}{|c|c|c|c|c|c|c|}
\hline Models & $\mathbf{C}_{\mathbf{B}}$ & $\mathbf{L} / \mathbf{B}$ & $\mathbf{B} / \mathbf{T}$ & $\mathbf{L} / \mathbf{\nabla}^{\mathbf{1 / 3}}$ & $\mathbf{W S A} / \mathbf{L}^{\mathbf{2}}$ & $\boldsymbol{\beta}_{\boldsymbol{M}}$ \\
\hline M1 & 0.50 & 10.40 & 1.50 & 6.69 & 0.16 & 23.14 \\
\hline M2 & 0.50 & 10.40 & 2.50 & 7.93 & 0.12 & 23.20 \\
\hline M 3 & 0.50 & 15.60 & 2.00 & 9.67 & 0.09 & 26.68 \\
\hline M 4 & 0.50 & 20.80 & 1.50 & 10.62 & 0.08 & 22.96 \\
\hline M 5 & 0.50 & 20.80 & 2.50 & 12.58 & 0.06 & 23.25 \\
\hline M 6 & 0.55 & 10.40 & 2.00 & 7.13 & 0.14 & 23.80 \\
\hline M 7 & 0.55 & 15.60 & 1.50 & 8.49 & 0.11 & 26.43 \\
\hline M 8 & 0.55 & 15.60 & 2.00 & 9.35 & 0.09 & 23.80 \\
\hline M 9 & 0.55 & 15.60 & 2.50 & 10.08 & 0.08 & 19.15 \\
\hline M 10 & 0.55 & 20.60 & 2.00 & 11.33 & 0.07 & 23.80 \\
\hline M 11 & 0.60 & 10.40 & 1.50 & 6.30 & 0.17 & 24.53 \\
\hline M 12 & 0.60 & 10.40 & 2.50 & 7.47 & 0.13 & 16.21 \\
\hline M 13 & 0.60 & 15.60 & 1.50 & 8.24 & 0.11 & 24.02 \\
\hline M 14 & 0.60 & 15.60 & 2.00 & 9.09 & 0.09 & 20.58 \\
\hline M 15 & 0.60 & 20.80 & 1.50 & 9.98 & 0.08 & 24.02 \\
\hline M 16 & 0.60 & 20.80 & 2.50 & 11.86 & 0.06 & 16.21 \\
\hline M17 & 0.55 & 13.00 & 1.86 & 8.07 & 0.11 & 24.53 \\
\hline M18 & 0.59 & 17.20 & 1.60 & 9.12 & 0.10 & 24.66 \\
\hline
\end{tabular}

Table 11: Summary of Regression Coefficients for Equation 13.

\begin{tabular}{|c|c|c|c|c|c|}
\hline Fn & $\boldsymbol{\alpha}$ & $\boldsymbol{\beta}_{\mathbf{1}}$ & $\boldsymbol{\beta}_{\mathbf{2}}$ & $\boldsymbol{\beta}_{\mathbf{3}}$ & $\boldsymbol{\beta}_{\mathbf{4}}$ \\
\hline 0.4 & 2.507751 & -2.255878 & -1.819332 & 0.921796 & -0.026670 \\
\hline 0.5 & 2.448887 & -2.424720 & -1.582805 & 0.861936 & -0.278595 \\
\hline 0.6 & 2.231476 & -2.442478 & -1.528469 & 0.931836 & -0.232555 \\
\hline 0.7 & 1.898569 & -2.402987 & -1.489982 & 0.961013 & -0.129839 \\
\hline 0.8 & 1.543052 & -2.351095 & -1.442334 & 0.965683 & -0.046904 \\
\hline 0.9 & 1.208420 & -2.308691 & -1.384697 & 0.966650 & -0.004858 \\
\hline 1.0 & 0.911271 & -2.279982 & -1.317368 & 0.979194 & 0.004593 \\
\hline 1.1 & 0.063404 & -2.257688 & -1.240560 & 0.995197 & -0.004378 \\
\hline 1.2 & 0.391235 & -2.242743 & -1.155136 & 1.021166 & -0.017454 \\
\hline 1.3 & 0.162273 & -2.233282 & -1.050167 & 1.036256 & -0.027712 \\
\hline 1.4 & 0.002700 & -2.235047 & -0.908676 & 1.119485 & -0.031137 \\
\hline 1.5 & -0.028588 & -2.268397 & -0.692935 & 1.326583 & -0.035505 \\
\hline
\end{tabular}




\section{Round Bilge Catamaran Series of SchWetz ANd SAHOO (2002)}

The research program was devised to:

- Examine variations in $\mathrm{C}_{\mathrm{W}}$ using $\mathrm{CFD}$, while modifying basic hull parameters and maintaining the same displacement and LCB position.

- Examine variations in $\mathrm{C}_{\mathrm{W}}$ using $\mathrm{CFD}$, while modifying basic hull parameters, including the displacement and LCB.

- Compare $\mathrm{C}_{\mathrm{W}}$ results of CFD with results from towing tank tests and develop regression model..

The series of symmetrical hull shapes used in this study were generated by the authors, and are believed to closely represent the hull forms being used in industry at the moment. The models are not mathematical in nature, and do not form part of any published systematic series. The body plans of models 1 to 10 are presented in Figure 3 and a summary of the particulars are presented in Table 12.

Table 12: Model Parameters (Demi-hull)

\begin{tabular}{|c|c|c|c|c|c|c|c|}
\hline Models & $\mathbf{L} / \mathbf{B}$ & $\mathbf{B} / \mathbf{T}$ & $\mathbf{C}_{\mathbf{B}}$ & $\mathbf{L} / \boldsymbol{\nabla}^{\mathbf{1 / 3}}$ & $\mathbf{i}_{\mathbf{E}}(\mathbf{d e g})$ & $\begin{array}{c}\text { LCB/L in \% } \\
\text { from transom }\end{array}$ & $\mathbf{L C B} / \mathbf{L C F}$ \\
\hline M1-RB & 15.00 & 2.11 & 0.55 & 9.56 & 8.68 & 42.00 & 1.00 \\
\hline M2-SS & 15.20 & 1.79 & 0.49 & 9.56 & 8.66 & 45.00 & 1.12 \\
\hline M3-SS & 15.10 & 1.73 & 0.46 & 9.54 & 3.15 & 42.00 & 1.10 \\
\hline M4-SS & 15.00 & 1.71 & 0.46 & 9.53 & 2.10 & 42.00 & 1.20 \\
\hline M5-CH & 15.30 & 2.07 & 0.54 & 9.55 & 9.16 & 42.00 & 0.98 \\
\hline M6-CH & 14.80 & 2.31 & 0.66 & 9.18 & 16.60 & 44.00 & 0.96 \\
\hline M7-CH & 14.90 & 2.31 & 0.65 & 9.20 & 13.60 & 44.00 & 0.97 \\
\hline M8-CH & 8.80 & 1.47 & 0.52 & 6.30 & 38.00 & 49.00 & 0.99 \\
\hline M9-CH & 10.40 & 1.73 & 0.61 & 7.08 & 15.00 & 47.00 & 1.03 \\
\hline M10-CH & 13.00 & 1.77 & 0.68 & 7.60 & 15.00 & 40.00 & 0.92 \\
\hline
\end{tabular}
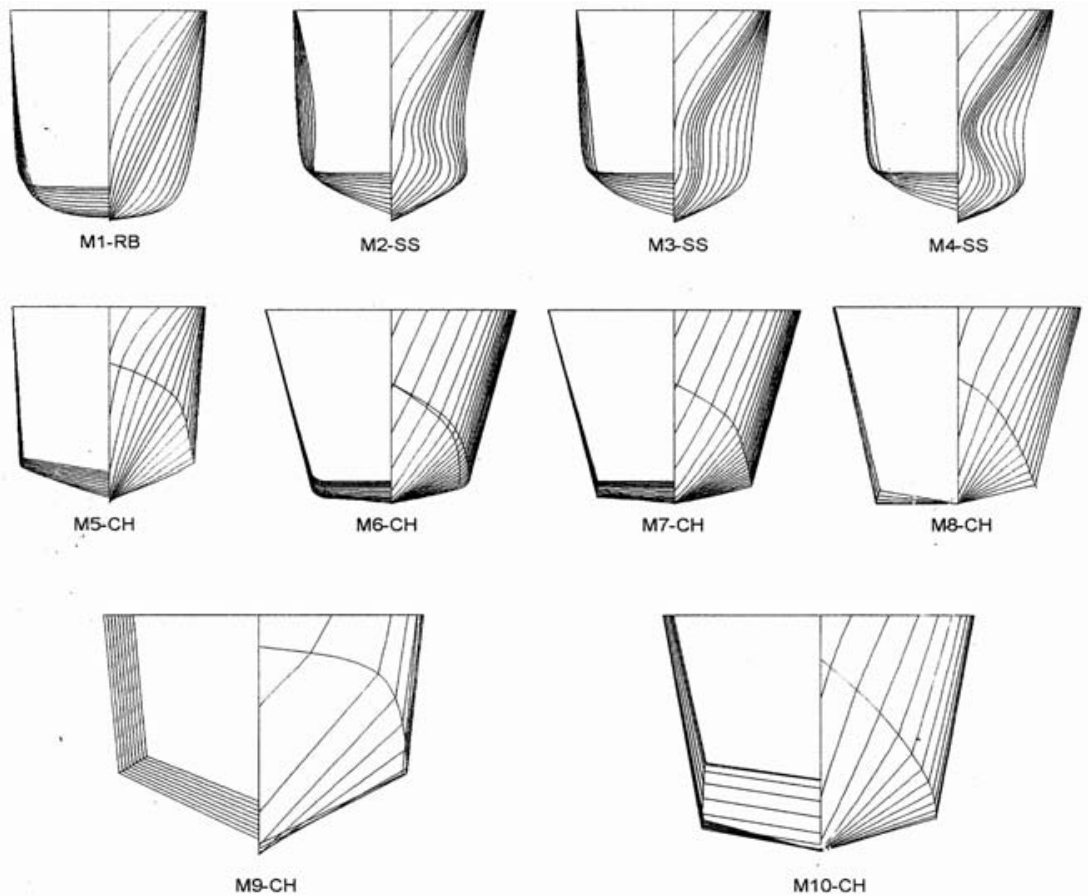

Figure 3: Body Plans of Models (Schwetz and Sahoo (2002)

Following a review of current vessel dimensions, hull model M1-RB was created which has a round bilge hull form and was designed to have an overall length of 50 meters, with a transom stern to accommodate two sets of Kamewa 71 series water jets on each demi-hull. The displacement was 255 
tonnes, with the LCB located at around $42 \%$ and $44 \%$ of the waterline length, referenced from the transom. An amount of semi-swathness was added to model M1-RB to create models M2-SS, M3-SS and M4-SS, where the amount of semi-swathness increases from models M2 to M4. Model M5-CH was generated from model M1-RB by replacing the round bilge with a single chine, while maintaining the same displacement and LCB. Hull model M7-CH contains a hard chine and hull model M6-CH was generated from model $\mathrm{M} 7-\mathrm{CH}$ by rounding or filleting the hard chine, while maintaining the same displacement and LCB as models M1 to M5. Models M8-CH, M9-CH and M10-CH were included to examine the general effects of reducing $\mathrm{L} / \nabla^{1 / 3}$. The displacements and LCB vary for models M8-CH to $\mathrm{M} 10-\mathrm{CH}$. Further details on regression equations have been provided in Appendix V.

\section{Round Bilge Catamaran Series of Sahoo, Browne and Salas (2004)}

The authors have expanded on the work carried out by Schwetz and Sahoo (2002) by conducting further work on a systematic series of round bilge catamaran hull forms and subjecting these to CFD analysis. The systematic series that was used for this analysis is based on typical hull forms used by the high-speed ferry industry in Australia. A parametric transformation procedure was used to produce the desired demi-hull series. Table 13 illustrates the geometrical parameters of the demi-hull series developed. For each model, hydrostatic information was extracted as presented in Table 14, containing parameters relevant to the regression analysis.

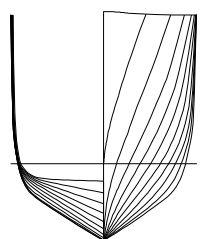

Model 1

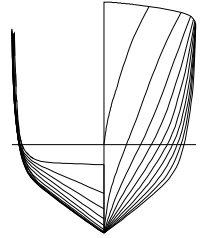

Model 4

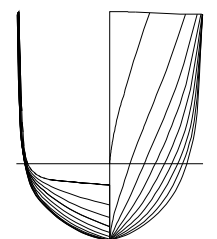

Model 2

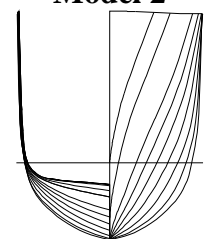

Model 5

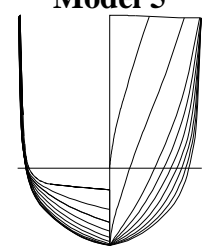

Model 7

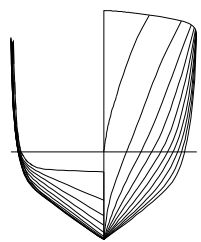

Model 3

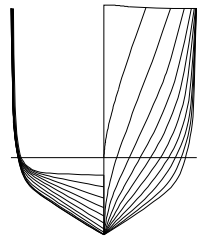

Model 6

Figure 4: Body Plans of Model 1 to 7 [Sahoo, Browne and Salas (2004)]

It may be noted that LCB and LCF locations are with respect to the transom. The systematic series of demi-hulls thus produced was confined to s/L ratio between 0.2 and 0.4 while speed range (Fn) was constrained between 0.2 and 1.0. The body plans of models developed during this research study are illustrated in Figure 4. The regression equations to determine the $\mathrm{C}_{\mathrm{W}}$ are presented in Appendix VI.

Table 13: Systematic Series of Catamarans [Sahoo, Browne and Salas (2004)]

\begin{tabular}{|c|c|c|c|c|c|c|c|}
\hline Model & $\mathbf{1}$ & $\mathbf{2}$ & $\mathbf{3}$ & $\mathbf{4}$ & $\mathbf{5}$ & $\mathbf{6}$ & $\mathbf{7}$ \\
\hline $\mathbf{L} / \mathbf{B}$ & 15 & 15 & 15 & 15 & 12.5 & 12.5 & 10 \\
\hline $\mathbf{B} / \mathbf{T}$ & 1.5 & 1.5 & 2.5 & 2.5 & 1.5 & 2.5 & 2.5 \\
\hline $\mathbf{C}_{\mathbf{B}}$ & 0.40 & 0.45 & 0.50 & 0.40 & 0.45 & 0.45 & 0.45 \\
\hline $\mathbf{L} / \nabla^{1 / 3}$ & 9.45 & 9.08 & 10.40 & 11.20 & 8.04 & 9.54 & 8.22 \\
\hline
\end{tabular}

\section{RESISTANCE ESTIMATION METHOD OF SUbRAMANIAN AND JOY (2004)}

The authors have illustrated a procedure for rapid development of hull form and preliminary prediction of resistance of high-speed catamarans with slender demi-hulls. They have made use of Michell's 
integral for slender vessels to estimate the wave resistance of demi-hulls, which combined with the average form factor value of $1.42(1+\gamma \mathrm{k})$ for ITTC ' 57 friction line would provide the total resistance. The theoretical details of models generated and tested numerically are shown in Table 15 below:

Table 14: Hydrostatics of Systematic Series [Sahoo, Browne and Salas (2004)]

\begin{tabular}{|c|c|c|c|c|c|c|c|c|c|}
\hline Model & $\begin{array}{c}\text { Length } \\
(\mathbf{m})\end{array}$ & $\begin{array}{c}\text { Beam } \\
(\mathbf{m})\end{array}$ & $\begin{array}{c}\text { Draught } \\
(\mathbf{m})\end{array}$ & $\begin{array}{c}\text { Displacement } \\
(\mathbf{\Delta}) \\
(\mathbf{t o n n e s})\end{array}$ & $\begin{array}{c}\mathbf{i}_{\mathbf{E}} \\
(\mathbf{d e g})\end{array}$ & $\begin{array}{c}\boldsymbol{\beta} \\
(\mathbf{d e g})\end{array}$ & $\begin{array}{c}\text { WSA } \\
\left(\mathbf{m}^{\mathbf{2}}\right)\end{array}$ & $\begin{array}{c}\text { LCB } \\
(\mathbf{m})\end{array}$ & $\begin{array}{c}\text { LCF } \\
(\mathbf{m})\end{array}$ \\
\hline $\mathbf{1}$ & 50.00 & 3.33 & 2.22 & 151.93 & 5.43 & 42.99 & 246.10 & 22.30 & 20.70 \\
\hline $\mathbf{2}$ & 50.00 & 3.33 & 2.22 & 170.91 & 7.18 & 44.32 & 256.20 & 22.27 & 21.54 \\
\hline $\mathbf{3}$ & 50.00 & 3.33 & 1.33 & 113.90 & 7.03 & 24.94 & 195.89 & 22.34 & 21.41 \\
\hline $\mathbf{4}$ & 50.00 & 3.33 & 1.33 & 91.08 & 4.00 & 23.32 & 181.97 & 22.29 & 19.99 \\
\hline $\mathbf{5}$ & 50.00 & 4.00 & 2.67 & 246.10 & 8.60 & 44.11 & 307.57 & 22.27 & 21.54 \\
\hline $\mathbf{6}$ & 50.00 & 4.00 & 1.60 & 147.69 & 8.60 & 30.37 & 231.71 & 22.27 & 21.54 \\
\hline $\mathbf{7}$ & 50.00 & 5.00 & 2.00 & 230.77 & 10.71 & 30.37 & 289.80 & 22.27 & 21.54 \\
\hline
\end{tabular}

Table 15: Geometric Parameters of Vessels [Subramanian and Joy (2004)]

\begin{tabular}{|c|c|c|c|c|c|c|}
\hline Parameter & $\mathbf{L} / \mathbf{B}$ & $\mathbf{B} / \mathbf{T}$ & $\mathbf{L} / \mathbf{V}^{\mathbf{1 / 3}}$ & $\mathbf{C}_{\mathbf{B}}$ & $\mathbf{C}_{\mathbf{P}}$ & $\left.\mathbf{S} \mathbf{( m}^{\mathbf{2}}\right)$ \\
\hline Form 1 & 9.37 & 1.79 & 6.69 & 0.57 & 0.60 & 130.40 \\
\hline Form 2 & 8.33 & 1.93 & 6.69 & 0.49 & 0.52 & 131.10 \\
\hline Form 3 & 7.69 & 2.29 & 6.69 & 0.49 & 0.67 & 125.20 \\
\hline Form 4 & 12.50 & 1.88 & 8.92 & 0.48 & 0.67 & 155.50 \\
\hline Form 5 & 11.76 & 2.06 & 8.92 & 0.47 & 0.65 & 152.40 \\
\hline Form 6 & 1.11 & 2.25 & 8.92 & 0.46 & 0.62 & 151.10 \\
\hline Form 7 & 15.62 & 2.13 & 11.15 & 0.45 & 0.94 & 173.00 \\
\hline Form 8 & 13.89 & 2.57 & 11.15 & 0.43 & 0.92 & 169.20 \\
\hline Form 9 & 12.50 & 3.20 & 11.15 & 0.43 & 0.90 & 166.53 \\
\hline
\end{tabular}

\section{Calculation of Wave Resistance Coefficient}

The wave resistance coefficients were calculated for each hull model using SHIPFLOW, a computational fluid dynamics (CFD) program developed by FLOWTECH International of Sweden.

SHIPFLOW was developed as a pioneering effort to address the complication of fluid flow characteristics around moving objects both in fully submerged situation and in free surface situation. Even though SHIPFLOW is intended specially for marine applications, it has also been extended to sufficiently solve closely related problems such as highly turbulent flow around automobiles.

The theoretical wave resistance coefficient, $\mathrm{C}_{\mathrm{W}}$, is calculated by splitting the flow into three regions where an efficient approximation of the flow equations may be made and a complete flow calculation may be accomplished in a few hours using the potential flow, as described by Larsson (1993). Figure 2 represents the zonal approach or regions used by SHIPFLOW to maximise computational efficiency.

Major areas in which SHIPFLOW has been found to be highly applicable include calculation of ship hull resistance both viscous and wave-related, development of wave profiles and sequential matters consisting of trim and sinkage characteristics, changes in velocities and pressure field around objects such as propellers. Some of these problems remain a challenge to researchers in order to produce more sophisticated CFD program to handle the complex phenomenon of fluid and object interactions.

According to Larsson (1993), the development of SHIPFLOW is based on three major methods each applied in its most efficient zone of fluid condition:

(i) Zone 1: Potential flow method.

(ii) Zone 2: Boundary layer method.

(iii) Zone 3: Navier-Stokes method. 
The laminar flow starts from the stagnation point, diverge gradually as it moves downstream, and when they reach the transition point where the viscous force is insufficiently strong to bond the streamlines, it breaks down and become turbulent.

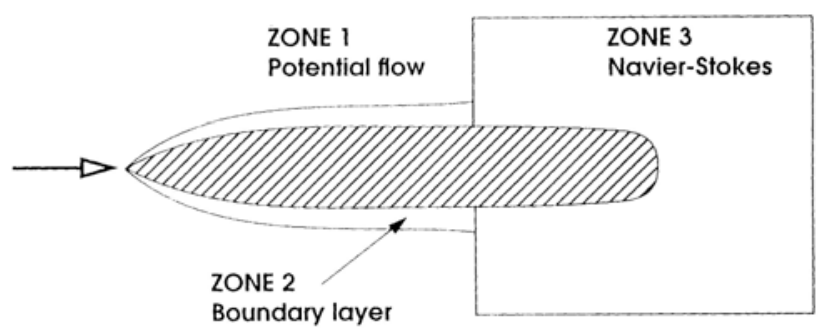

Figure 5: Zonal Distribution for Fluid Flow Computation in SHIPFLOW

Potential flow method is used to analyze the fluid-flow in the outermost area of the free surface designated as Zone 1 in Figure 5. In this zone the fluid-flow is treated as continuous streamlines starting from fore end of the ship, and extending up to the aft end. The region of free surface that describes the thin boundary layers along the ship hull is defined as Zone 2. The nature of fluid-flow change as the fluid moves along the hull in this region. The boundary layer theory is used to compute the fluid characteristics in zone 2 .

The remaining region of the free surface is fully turbulent and will have wakes. It is specified as zone 3 and extending far aft from the transition point, which is usually about amidships. Navier-Stokes theory is applied in this zone to calculate the energy and hence the corresponding resistance incurred.

The free group represents the free surface. The free surface can be considered as the water surrounding the body group, which is used to model the waves created. Therefore it is necessary to create a free surface that extends forward of the bow, well aft of the model (approximately two wave lengths), and a considerable distance abeam of the vessel. After the limits of the free surface have been introduced, it is necessary to once again define the number of stations along the length of the free surface and the number of points across each station to create the grid.

The transom group represents a part of the free surface which extends directly aft of the transom. This group is therefore quite long and only as wide as the vessel. As in the previous section, it is necessary to define the number of stations and points required to produce a grid. For consistency, the number of stations aft of the body must be the same for the free surface as it is for the transom group so that the panels are aligned.

The module XPAN is the solver that iteratively converges on the value of co-efficient of wave resistance. It is therefore necessary to input the maximum number of iterations that are to be used. In addition to this, the type of solver that will be used must be specified. The non-linear solver will generally produce a more accurate result than the linear solver, however it is more unstable particularly at high speeds and the solution may not converge. If reference is not made to the type of solver then the linear solver is used as the default. The other important feature of XPAN is whether the model is enabled to freely sink and trim. It is important to note that SHIPFLOW undergoes it analysis by nondimensionalising the vessel down to a model of unity. Therefore all of the co-ordinates are nondimensionalised by the length between perpendiculars $\mathrm{L}_{\mathrm{PP}}$. As mentioned XMESH module enables the user of SHIPFLOW to construct a grid of panels to illustrate the scenario to be tested. Due to the flexibility of SHIPFLOW to be applied to many different applications, it can produce varying results, which will not match model testing, or full-scale data. The program will produce an accurate result of co-efficient of wave resistance based on the grid supplied, however if the grid is not well set-up the result does not have much validity.

One of the major limitations of SHIPFLOW is its inability to model spray and wave-breaking phenomena at high speeds with a Froude number of 1.0 considered as the upper limit. Therefore the investigation has been restricted to this speed. When considering the validity of results there are two key aspects, the precision and the accuracy. If SHIPFLOW is used correctly very precise results may 
be obtained however these results cannot be considered as accurate until they have been scaled according to some model testing or full-scale data. Therefore, when constructing the grid in SHIPFLOW the aim is to achieve precise results, which can then be altered for accuracy.

At low Froude numbers the transom wave has a small wavelength and a large wave height. Conversely, at high Froude numbers the transom wave has a large wavelength with small wave amplitude. Therefore if a constant grid is applied to all of the models at the full range of speeds the degree of precision varies. Therefore caution must be taken when comparing results at different speeds. To overcome this problem, the grid must be systematically altered as the speed is increased to take into account the larger wavelength. This was achieved by increasing the free and transom surfaces further aft until two wavelengths are included as a guideline. On the other hand, at lower speeds it is not necessary to extend the free and transom surfaces further aft of the body group, but it will be necessary to include smaller panels in the grid to account for the significant changes in wave height.

If the grid is not altered it can be expected that as the Froude number is increased the results can be considered as becoming increasingly precise. However, as previously mentioned when the speed is increased SHIPFLOW becomes increasingly unstable in its ability to model spray and wave breaking phenomena. Therefore, using this software is a balance of stability and precision and to produce valid results an extensive amount of time is required to analyse the different scenarios. The change in grid density was applied to this analysis to account for changes in Froude numbers.

\section{RESULTS}

Only three vessels from the series tested by Molland et al (1994) coincided with the series produced for this analysis. It is observed that above a Froude number of 0.5 the correlation of results is extremely good. The NPL series tested by Molland et al (1994) is based on a mono-hull series that has been put into a catamaran configuration. The other problem with using this work is the insufficient information available in their paper on the hydrostatics of each model. The value especially for dead-rise amidships and half angle of entrance have been kept constant at $7^{\circ}$ and $30^{\circ}$ respectively for NPL models and regression analysis for comparison purposes, and therefore a closer correlation would hopefully exist when the input is more accurate.

It is interesting to note the variables that have been included in the different equations for each Froude Number for a catamaran and demi-hull. The main variable that becomes apparent as having the most influence on resistance is the wet volume slenderness ratio $\left(\mathrm{L} / \nabla^{1 / 3}\right)$. Half angle of entrance, dead-rise, and separation ratio are also significant throughout the speed range. The breadth to draft ratio becomes significant only at the higher speeds.

It is interesting to note the variables that have been included in the different equations for each Froude Number for a catamaran and demi-hull. The main variable that becomes apparent as having the most influence on resistance is the slenderness ratio $\left(\mathrm{L} / \nabla^{1 / 3}\right)$.

The form factor due to viscous resistance interference factor is another aspect of catamaran resistance that could be further analysed. The work by Armstrong (2000) is limited to the applicable range of low Froude numbers that can be used. Therefore if a similar analysis was undertaken with carefully monitored SHIPFLOW and model testing results, an equation for form factor of catamarans could be produced. This seems to be the least researched aspect of determining catamaran resistance.

We have attempted to demonstrate here an example of the results obtained so as to summarize and compare the different methods. For different values of the catamaran parameters, the program allows to plot the graphs of the predicted wave resistance coefficients vs. Froude number and of the power predicted vs. velocity. Results are split into two, so as to differentiate the single hard chine hulls and the round bilge hulls.

All the methods explained here have been integrated into the program, except the ones for which data were nor available (Millward's method (1992), Hanhirova, Rintala and Karppinen method (1995) and Subramanian and Joy method (2004)).

The results for a model catamaran with chine hull (particulars shown in Table 16) has been shown in Figure 6. 
Table 16: Parameters of a Chine Hull Catamaran Model

\begin{tabular}{|c|c|}
\hline$\Delta$ vessel & $1.369 \mathrm{E}-02$ \\
\hline$\Delta$ demi & $6.844 \mathrm{E}-03$ \\
\hline$\nabla$ demi & $6.678 \mathrm{E}-03$ \\
\hline $\mathrm{L}$ & 1.600 \\
\hline $\mathrm{T}$ & 0.073 \\
\hline B & 0.145 \\
\hline Separation s & 0.48 \\
\hline Half Angle of Entrance $\mathrm{i}_{\mathrm{E}}$ & 8 \\
\hline Dead rise angle $\beta_{M}$ & 30 \\
\hline LCB & 0.92 \\
\hline $\mathrm{LCF}$ & 0.95 \\
\hline $\mathrm{C}_{\mathrm{B}}$ & 0.397 \\
\hline Gravitational Constant (g) & 9.81 \\
\hline$v_{\text {sw }}$ & $1.1881 \mathrm{E}-06$ \\
\hline$\rho_{\text {SW }}$ & 1.025 \\
\hline WSA demi & 0.276 \\
\hline WSA cat & 0.553 \\
\hline $\mathrm{C}_{\mathrm{A}}$ & 4.00E-04 \\
\hline Transom Wedge & 10 \\
\hline$L / V^{/ 3}$ & 8.497 \\
\hline$B / T$ & 2.000 \\
\hline$L C B / W L$ & 10.00 \\
\hline$L C B / L C F$ & 0.97 \\
\hline$s / L$ & 0.300 \\
\hline$L / B$ & 11.0 \\
\hline
\end{tabular}

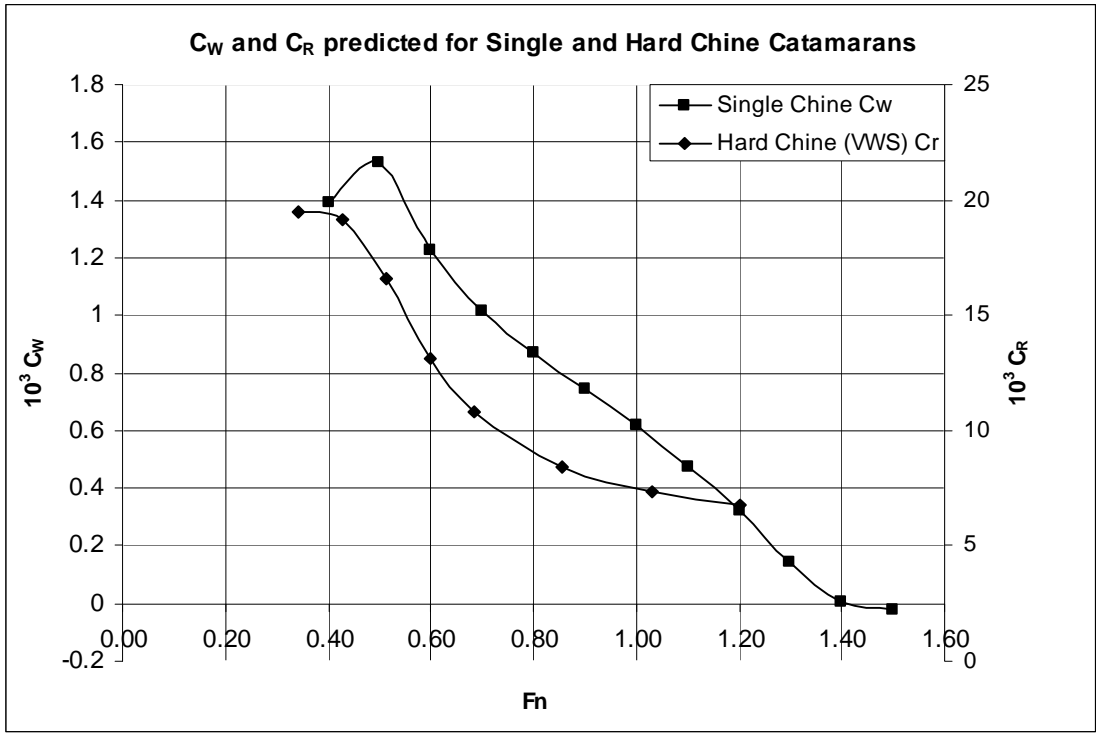

Figure 6: Comparison of $C_{W}$ against $C_{R}$ values of $\operatorname{Zips(1995)~}$

The results obtained from the different methods are very close and reliable. So these methods can easily be used for a pre-dimensioning. The only limit of these methods is the range of the catamaran parameters. Indeed they are different for each method, and if they are not respected the results can loose their numerical reliability. 


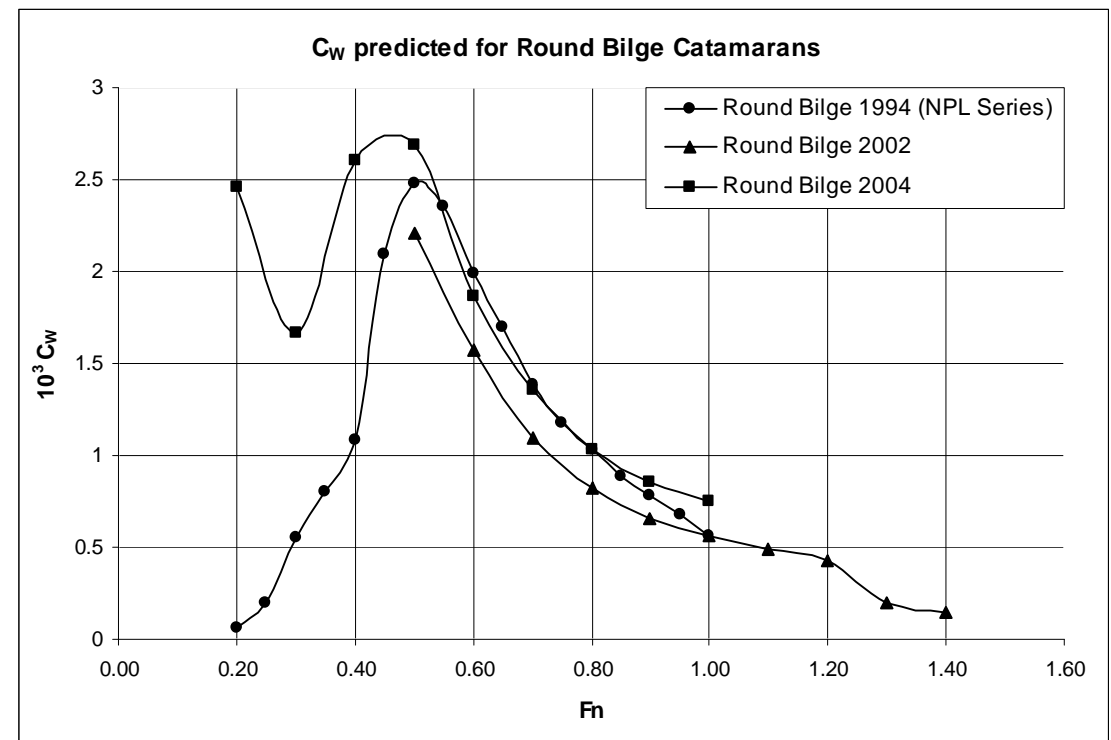

Figure 7: Comparison of Round Bilge Catamaran Hull Forms against Results of Catamaran Hull Forms of Molland et al. (1994)

\section{FINAL REMARKS}

The variation of grid density must be very precise in order to obtain accurate results over the whole speed range. Therefore time must be spent before analysis to set-up a grid for each Froude number so that the results are consistently precise. In order to perform suitable analysis on round bilge catamaran hull forms the constraints as shown in Table 10 should be strictly adhered to.

In order to calculate the total resistance, if actual data is unavailable, the following empirical formulae may be used:

Wetted Surface Area:

$S=1.7 L T+\frac{\nabla}{T} m^{2}$ as per Mumford

$S=\frac{\nabla}{B}\left[\frac{1.7}{C_{B}-0.2\left(C_{B}-0.65\right)}+\frac{B}{T}\right] m^{2}$

\section{CONCLUSIONS AND DISCUSSION}

In view of the analysis and validation process undertaken in this research work the following conclusions can be drawn:

- A systematic series of round bilge catamaran hull forms have been designed and wave resistance coefficients for demi-hull as well as catamaran hull form configurations have been determined using CFD (SHIPFLOW) for a range of Froude numbers.

- A regression analysis has been performed based on CFD results and has been compared with experimental results of NPL series hull forms as conducted by Molland et al (1994).

- It appears that the regression equation is robust enough as it compares favorably, specially at $0.5<\mathrm{Fn}<1.0$, with experimental results for the three NPL models whose geometrical parameters closely match the constraints of the regression analysis.

- It is expected that in Part II, the paper will attempt to validate the theoretical results against experimental results from a random selection of catamaran hull forms.

It is imperative to note that a limited number of models have been created in this instance, which implies that the range could be further enlarged and more rigorous validation is required against experimental results. 


$\begin{array}{ll}\text { Abbreviations } \\ \text { CFD } & \text { Computational Fluid Dynamics } \\ \text { LCB } & \text { Longitudinal center of buoyancy, reference from the transom } \\ \text { LCF } & \text { Longitudinal center of floatation, reference from the transom } \\ \text { DWL } & \text { Design waterline } \\ \text { ITTC } & \text { International Towing Tank Conference } \\ \text { WSA } & \text { Wetted Surface Area }\end{array}$

\section{Nomenclature}

\begin{tabular}{|c|c|}
\hline $\mathrm{A}_{\mathrm{AP}}$ & Area at aft perpendicular \\
\hline $\mathrm{A}_{\mathrm{FP}}$ & Area at forward perpendicular \\
\hline$A_{X}$ & Area at maximum transverse section \\
\hline $\mathrm{B}_{\mathrm{X}}$ & Breadth at maximum transverse section \\
\hline B & Demihull beam at the waterline \\
\hline $\mathrm{B} / \mathrm{T}$ & Beam-Draught ratio \\
\hline $\mathrm{C}_{\mathrm{A}}$ & incremental resistance coefficient \\
\hline $\mathrm{C}_{\mathrm{B}}$ & Block Coefficient $C_{B}=\frac{\nabla}{L \cdot B \cdot T}$ \\
\hline $\mathrm{C}_{\mathrm{F}}$ & ITTC' 57 ship model correlation line $C_{F}=\frac{0.075}{\left(\log _{10} R n-2\right)^{2}}$ \\
\hline $\mathrm{C}_{\mathrm{P}}$ & Prismatic coefficient \\
\hline $\mathrm{C}_{\mathrm{M}}$ & Midship coefficient \\
\hline $\mathrm{C}_{\mathrm{W}}$ & Wave resistance coefficient \\
\hline $\mathrm{C}_{\mathrm{R}}$ & Residuary resistance coefficient \\
\hline $\mathrm{C}_{\mathrm{T}}$ & Total resistance coefficient \\
\hline $\mathrm{C}_{\nabla}$ & Volumetric Coefficient \\
\hline$\Delta \mathrm{C}_{\mathrm{W}}$ & Wave resistance coefficient correction \\
\hline $\mathrm{F}_{\mathrm{n}}$ & Froude number (based on length) \\
\hline$F_{n \nabla / 2}$ & Froude number based on volumetric displacement of demi-hull \\
\hline G & Acceleration due to gravity \\
\hline $\mathrm{i}_{\mathrm{E}}$ & Half waterline entry angle \\
\hline $\mathrm{L}$ or $\mathrm{L}_{\mathrm{WL}}$ & Waterline length \\
\hline $\mathrm{L} / \mathrm{B}$ or $\mathrm{L}_{\mathrm{WL}} / \mathrm{B}_{\mathrm{XDH}}$ & Length-beam ratio (demi-hull) \\
\hline $\mathrm{L} / \nabla^{1 / 3}$ & Slenderness ratio \\
\hline LCF & Longitudinal center of flotation from transom \\
\hline LCB & Longitudinal center of buoyancy from transom \\
\hline $\mathrm{P}_{\mathrm{E}}$ & Effective power \\
\hline $\mathrm{R}_{\mathrm{W}}$ & Wave resistance \\
\hline $\mathrm{R}_{\mathrm{F}}$ & Frictional resistance \\
\hline $\mathrm{R}_{\mathrm{T}}$ & Total resistance \\
\hline S & Separation (measured between demi-hull centre planes) \\
\hline $\mathrm{s} / \mathrm{L}$ & Separation ratio (between demi-hulls) \\
\hline $\mathrm{S}_{\mathrm{W}}$ & Wetted surface area \\
\hline $\mathrm{T}_{\mathrm{AP}}$ & Draft at aft perpendicular \\
\hline $\mathrm{T}_{\mathrm{X}}$ & Draft at maximum transverse section \\
\hline g & Acceleration due to gravity $9.81 \mathrm{~m} / \mathrm{s}^{2}$ \\
\hline $1+\mathrm{k}$ & Form factor \\
\hline $1+\gamma \mathrm{k}$ & viscous form factor \\
\hline$\beta_{M}$ & Deadrise angle at amidships \\
\hline$\delta_{\mathrm{W}}$ & Transom wedge angle \\
\hline$\varepsilon_{\mathrm{R}}$ & Residual drag-weight ratio \\
\hline$\phi$ & Factor for pressure field change \\
\hline$\sigma$ & Velocity augmentation factor \\
\hline$\gamma$ & Viscous interference factor \\
\hline$\rho$ & Fluid density \\
\hline$\tau$ & Wave resistance interference factor \\
\hline v & Kinematic viscosity of fluid \\
\hline
\end{tabular}


$\begin{array}{ll}\Delta & \text { Displacement } \\ \nabla & \text { Volumetric displacement }\end{array}$

\section{ACKNOWLEDGEMENT}

The authors would like to express their sincere gratitude to The Australian Maritime College, Australia and The University of Austral, Chile for their support, encouragement throughout the course of this research work. They also want to extend sincere gratitude to Nick Browne of BMT Defence Services, Australia and David Pontaut from the ENSIETA engineering school (Brest, France), who have done some of the regressions (catamaran form factor and NPL series) and developed the spread sheets which calculate the wave resistance coefficient and the power prediction for several methods (NPL Series, VWS Hard Chine, Single Chine 2001 and Round Bilge 2002). Without their valuable contributions this paper would not have seen the light of the day.

\section{REFERENCES}

Armstrong, N.A (2000), On the Viscous Resistance and Form Factor of High-Speed Catamaran-Ferry Hull Forms, Ph.D Thesis, The University of New South Wales, Sydney, Australia.

Drewry Shipping Consultants (1997), FAST FERRIES: Shaping the Ferry Market for the $21^{\text {st }}$ Century. Drewry Shipping Consultants Ltd., London.

Hanhirova, K., Rintala, S. and Karppinen, T. (1995), Preliminary Resistance Prediction Method for Fas Mono- and Multihull Vessels, Proc. of High-Speed Vessels for Transport and Defence, Royal Society of Arts, London.

Insel, M. and Molland, A.F. (1992), An Investigation into Resistance Components of High-Speed Displacement Catamarans, Trans. of Royal Institute of Naval Architects, Vol.134, pp 1-20

Molland, A.F., Wellicome, J.F. and Couser, P.R. (1994), Resistance Experiments on a Systematic Series of High Speed Displacement Catamaran Forms: Variation of Length-Displacement Ratio and Breadth-Draft Ratio, Ship Science Report No.71, University of Southampton, UK.

Pham, X.P., Kantimahanthi, K. and Sahoo, P.K. (2001), Wave Resistance Prediction of Hard-Chine Catamarans through Regression Analysis, Proc. $2^{\text {nd }}$ International Euro Conference on High Performance Marine Vehicles (HIPER'01), Hamburg, Germany, pp 382-394

Schwetz, A, Sahoo, P K. (2002), Wave Resistance of Semi-Displacement High Speed Catamarans Through CFD and Regression Analysis, Proc. $3^{\text {rd }}$ International Euro Conference on High Performance Marine Vehicles (HIPER'02), Bergen, Norway, pp 355-368.

Subramanian, V.A. and Joy, P. (2004), A Method for rapid Hull Form Development and Resistance Estimation of Catamarans, Trans. of Marine Technology, Spring, Vol. 38, No. 1, pp 5-11

SHIPFLOW User's Manual, Flowtech International, Edition 1, December 2003.

Zips, J.M. (1995), Numerical Resistance Prediction based on Results of the VWS Hard Chine Catamaran Hull Series '89, Proc. $4^{\text {th }}$ International Conference on Fast Sea Transportation (FAST '95), Luebeck, Germany,Vol 1, pp 67-74

\section{APPENDIX I}

As per Armstrong (2000) the form factors are given by

\begin{tabular}{|l|l|l|}
\hline \multicolumn{1}{|c|}{ Parameter } & \multicolumn{1}{|c|}{ Equation } & \multicolumn{1}{c|}{ Validity } \\
\hline $1+\mathrm{k}$ & $0.65+350(\mathrm{Fn})^{-0.67}(\mathrm{~B} / \mathrm{T})^{0.15}(\mathrm{~L} / \mathrm{B})^{-1.5}\left(\mathrm{~L} / \nabla^{1 / 3}\right)^{-1.5}$ & $0.5<\mathrm{Fn}<1.0$ \\
& & $6<\mathrm{L} / \nabla^{1 / 3}<8$ \\
& & $12<\mathrm{L} / \mathrm{B}<15$ \\
& & $1.5<\mathrm{B} / \mathrm{T}<2.5$ \\
\hline$(1+\mathrm{k})_{\text {model }}$ & $1.45-0.139\left(\mathrm{~L} / \nabla^{1 / 3}\right)^{0.6}(\mathrm{~B} / \mathrm{T})^{-0.1}$ & $3 \times 10^{6}<\mathrm{Rn}<5 \times 10^{6}$ \\
\hline
\end{tabular}




\begin{tabular}{|l|l|l|}
\hline & & $6.5<\mathrm{L} / \nabla^{1 / 3}<9.5$ \\
& & $\begin{array}{l}1.5<\mathrm{B} / \mathrm{T}<2.5 \\
0.6<\mathrm{Fn}<1.0\end{array}$ \\
\hline$(1+\mathrm{k}) \operatorname{ship}$ & $1.72-\mathrm{f}\left(\mathrm{L} / \nabla^{1 / 3}\right)^{\mathrm{g}}(\mathrm{B} / \mathrm{T})^{-0.1}$ & $10^{9}<\mathrm{Rn}<2 \times 10^{9}$ \\
\hline $\mathrm{f}$ & $-2.25 \mathrm{Fn}^{2}+4.47 \mathrm{Fn}-1.61$ & $\mathrm{Fn}<1.0$ \\
\hline $\mathrm{f}$ & 0.61 & $\mathrm{Fn}>1.0$ \\
\hline $\mathrm{g}$ & $0.76-1.09 \mathrm{f}$ & \\
\hline
\end{tabular}

\section{APPENDIX II}

Detailed regression analysis had been performed on these series (Zips 91995)) and in order to carry out resistance prediction some of the parameters have been reproduced below:

ㅁ Variables defined as $\mathrm{X} 1=\left(\mathrm{L}_{\mathrm{WL}} / \mathrm{B}_{\mathrm{XDH}}-10.55\right) / 3, \mathrm{X} 2=\left(\beta_{\mathrm{M}}-27^{0}\right) / 11$ and $\mathrm{X} 3=\delta_{\mathrm{W}} / 12$

- Length-displacement ratio of demihull is given by:

$$
\frac{L_{W L}}{(\nabla / 2)^{1 / 3}}=7.651877+1.694413 * X 1+0.282139 * X 1^{2}-0.052496 * X 1^{2} * X 2
$$

Wetted surface area coefficient is given by: $\frac{S_{W(V=0)}}{\nabla^{2 / 3}}=C S * X S * 10$

$$
C S=\left[\begin{array}{l}
1.103767 \\
0.151489 \\
0.00983 \\
-0.009085 \\
0.008195 \\
-0.029385 \\
0.041762
\end{array}\right] X S=\left[\begin{array}{l}
1 \\
X 1 \\
X 2^{2} \\
X 1^{2} \\
X 1^{2} X 2 \\
X 1 X 2^{2} \\
X 1^{3} X 2
\end{array}\right]
$$

口 Residual drag-weight ratio is given by: $\varepsilon_{R}\left(F_{n \nabla / 2}\right)=\frac{\left(X R^{T} * C R\right)}{100}$

口 Vector of regression parameter XR is given by:

$$
X R=\left[\begin{array}{l}
X 0=1 \\
X 1=f\left(L_{W L} / B_{X D H}\right) \\
X 2=f\left(\beta_{M}\right) \\
X 3=f\left(\delta_{W}\right) \\
X 4=X 1^{2} \\
X 5=X 1^{3} \\
X 6=X 2^{2} \\
X 7=X 3^{1 / 2} \\
X 8=X 3^{1 / 3}
\end{array}\right] X R=\left[\begin{array}{l}
X 9=X 3^{1 / 4} \\
X 10=X 1 * X 2 \\
X 11=X 1 * X 6 \\
X 12=X 4 * X 6 \\
X 13=X 4 * X 2 \\
X 14=X 1 * X 3 \\
X 15=X 4 * X 7 \\
X 16=X 1 * X 9 \\
X 17=x 1^{*} X 7^{3} \\
X 18=X 2 * X 8
\end{array}\right]
$$

- Procedure for calculation is as follows:

- Given the following parameters $\mathrm{L}_{\mathrm{WL}} / \mathrm{B}_{\mathrm{XDH}}$ transformed to $\mathrm{X} 1, \beta_{\mathrm{M}}$ transformed to $\mathrm{X} 2$ and $\delta_{\mathrm{W}}$ transformed to $\mathrm{X} 3, \nabla, \mathrm{C}_{\mathrm{A}}, \rho$ and $\mathrm{v}$

$\circ$ Determine $\frac{L_{W L}}{(\nabla / 2)^{1 / 3}}, \frac{S_{W}(V=0)}{\nabla^{2 / 3}}$ and $\varepsilon_{R}\left(F_{n \nabla / 2}\right)$

$\circ \quad R_{n}=\frac{\left(\frac{L_{W L}}{(\nabla / 2)^{1 / 3}} \times F_{n \nabla / 2} \times\left(\frac{\nabla}{2} g\right)^{1 / 2}\right)}{v}$ 


$$
\begin{array}{ll}
\circ & C_{F}=\frac{0.075}{\left(\log R_{n}-2\right)^{2}} \\
\circ & R_{F}=\frac{\left(C_{F}+C_{A}\right) \rho F_{n \nabla / 2}{ }^{2} \times \frac{S_{W(V=0)}}{\nabla^{2 / 3}} \times \nabla \times g \times 2^{2 / 3}}{4} \\
\circ \quad R_{T}=R_{F}+\left(\varepsilon_{R} \times \nabla \times \rho \times g\right)
\end{array}
$$

\begin{tabular}{|c|c|c|c|c|c|c|c|c|}
\hline$F_{n \nabla / 2}$ & 1.00 & 1.25 & 1.50 & 1.75 & 2.00 & 2.50 & 3 & 3.50 \\
\hline \multirow{19}{*}{$C_{R}=$} & 2.348312 & 4.629531 & 5.635988 & 5.627470 & 5.690865 & 6.209794 & 7.243674 & 7.555179 \\
\hline & -0.706875 & -2.708625 & -2.371713 & -2.266895 & -2.500808 & -2.900769 & -3.246017 & -2.647421 \\
\hline & -0.272668 & -0.447266 & -0.328047 & -0.428999 & -0.422339 & -0.391296 & 0.000000 & 0.453125 \\
\hline & 0.586730 & 0.000000 & 0.000000 & 0.000000 & -0.288437 & -0.447655 & 0.000000 & 0.000000 \\
\hline & 0.256967 & 0.701719 & 0.349687 & 0.416250 & 0.571875 & 0.832031 & 0.554213 & 0.332042 \\
\hline & 0.000000 & 0.000000 & 0.165938 & 0.342187 & 0.496875 & 0.656719 & 1.196250 & 1.884844 \\
\hline & 0.000000 & 0.148359 & 0.000000 & 0.000000 & 0.000000 & 0.000000 & 0.000000 & -0.276875 \\
\hline & 0.000000 & 0.000000 & 0.000000 & 0.000000 & 0.000000 & 0.000000 & -1.877430 & 0.000000 \\
\hline & -0.152163 & 0.000000 & -0.251026 & -0.429128 & -0.450245 & -0.866917 & 0.000000 & 0.000000 \\
\hline & 0.000000 & 0.000000 & 0.000000 & 0.000000 & 0.000000 & 0.000000 & 0.000000 & -1.036289 \\
\hline & 0.000000 & 0.149062 & 0.090188 & 0.089625 & 0.076125 & 0.000000 & -0.332250 & -0.767250 \\
\hline & -0.151312 & -0.090188 & -0.135563 & -0.194250 & -0.190125 & -0.225938 & -0.211125 & 0.000000 \\
\hline & -0.059200 & -0.322734 & 0.000000 & 0.000000 & 0.000000 & 0.000000 & 0.000000 & 0.000000 \\
\hline & 0.000000 & -0.148359 & -0.096328 & 0.000000 & 0.000000 & 0.000000 & 0.000000 & 0.000000 \\
\hline & 0.000000 & 0.409500 & 0.484800 & 0.000000 & 0.817200 & 1.189350 & 1.007700 & 0.000000 \\
\hline & 0.000000 & 0.000000 & 0.000000 & 0.000000 & 0.000000 & 0.000000 & 0.588758 & 0.683505 \\
\hline & 0.000000 & 0.000000 & 0.000000 & 0.000000 & 0.000000 & 0.000000 & 0.000000 & -0.241426 \\
\hline & 0.000000 & 0.000000 & 0.000000 & 0.704463 & 0.000000 & 0.000000 & 0.000000 & 0.000000 \\
\hline & -0.083789 & 0.000000 & 0.000000 & 0.120516 & 0.137585 & 0.257507 & 0.000000 & 0.000000 \\
\hline
\end{tabular}

Table 17: Matrix of Regression Coefficients $C_{R}$ [Zips(1995)]

\section{APPENDIX III}

The wave resistance coefficient correction formula for low $\mathrm{L} / \mathrm{B}$ monohulls is:

$$
\begin{aligned}
& \Delta C_{W}=C_{R}-C_{W}=C_{0}+C_{1} \cos \left(\lambda F_{n}^{e}\right) \frac{B_{A P}}{B_{X}}+C_{2} F_{n}^{e} C_{\nabla} \exp \left(\frac{a}{F_{n}^{2}}\right)+C_{3} C_{\nabla}^{2} \cos \left(\lambda F_{n}^{e}\right) \\
& +C_{4} C_{\nabla} C_{P}+C_{5} F_{n}^{e} \cos \left(\lambda F_{n}^{e}\right) \log \left(90-i_{E}\right)+C_{6}\left[\cos \left(\lambda F_{n}^{e}\right)\right]^{2} C_{\nabla}+C_{7} F_{n}^{e} C_{X} \exp \left(\frac{a}{F_{n}^{2}}\right)+C_{8}\left(C_{\nabla}\right)^{2} \frac{B_{X}}{T_{X}}+ \\
& C_{9}\left[\log \left(90-i_{E}\right)\right]^{3}+C_{10} F_{n}^{e} \cos \left(\lambda F_{n}^{e}\right)+C_{11} F_{n}^{e} \cos \left(\lambda F_{n}^{e}\right) C_{P}+C_{12}\left[\exp \left(\frac{a}{F_{n}^{2}}\right)\right]^{2} \frac{T_{A P}}{T_{X}}+C_{13}\left(C_{X}\right)^{2} \frac{T_{A P}}{T_{X}}
\end{aligned}
$$

where $\lambda=a_{1} C_{P}+a_{2} C_{\nabla}$

The wave resistance coefficient correction formula for high L/B monohulls is: 
$\Delta C_{W}=C_{R}-C_{W}=C_{0}+C_{1} F_{n} \sin \left(\lambda F_{n}^{e}\right)+C_{2}\left[\cos \left(\lambda F_{n}^{e}\right)\right]^{2} \frac{A_{A P}}{A_{X}}+C_{3}\left[\sin \left(\lambda F_{n}^{e}\right)\right]^{2} C_{P}$

$\left.+C_{4}\left[\sin \left(\lambda F_{n}^{e}\right)\right]\right]^{2} \frac{T_{A P}}{T_{X}}+C_{5} F_{n}^{3}+C_{6}\left(C_{\nabla}\right)^{2} \cos \left(\lambda F_{n}^{e}\right)+C_{7} \frac{C_{P}^{2}}{F_{n}}+C_{8} \frac{\left(\frac{A_{A P}}{A_{X}}\right)^{2}}{F_{n}}+C_{9} \sin \left(\lambda F_{n}^{e}\left(\frac{T_{A P}}{T_{X}}\right)^{2}+\right.$

$C_{10} \cos \left(\lambda F_{n}^{e}\right)\left(\frac{T_{A P}}{T_{X}}\right)^{2}+C_{11} \frac{T_{A P}}{T_{X}} \frac{1}{F_{n}^{2}}+C_{12}\left[\log \left(90-i_{E}\right)\right]^{3}+C_{13} \cos \left(\lambda F_{n}^{e}\right) C_{\nabla} \frac{A_{A P}}{A_{X}}$

The wave resistance coefficient correction formula for catamaran is:

$$
\begin{aligned}
& \Delta C_{W}=C_{R}-C_{W}=C_{0}+C_{1}\left(C_{\nabla}\right)^{2} \frac{1}{F_{n}}+C_{2} C_{P}\left[\log \left(90-i_{E}\right)\right]+C_{3}\left[\cos \left(\lambda F_{n}^{e}\right)\right]^{2} \frac{B_{A P}}{B_{X}} \\
& +C_{4} C_{P}^{2} \log \left(90-i_{E}\right)+C_{5} C_{P}^{3}+C_{6}\left(\frac{T_{A P}}{T_{X}}\right)^{2} \sin \left(\lambda F_{n}^{e}\right)+C_{7}\left(\frac{B_{A P}}{B_{X}}\right)^{2} \sin \left(\lambda F_{n}^{e}\right) \\
& +C_{8} C_{P}^{2}+C_{9} C_{\nabla}^{2}+C_{10}\left[\sin \left(\lambda F_{n}^{e}\right)\right]^{2} \cos \left(\lambda F_{n}^{e}\right)+C_{11} \cos \left(\lambda F_{n}^{e}\right) \sin \left(\lambda F_{n}^{e}\right) \exp \left(-\frac{w}{B}\right) \\
& +C_{12} \exp \left(-\frac{w}{B}\right)^{2} C_{\nabla}+C_{13}\left[\cos \left(\lambda F_{n}^{e}\right)\right]^{2} \frac{T_{A P}}{T_{X}}+C_{14}\left[\cos \left(\lambda F_{n}^{e}\right)\right]^{2} \sin \left(\lambda F_{n}^{e}\right) \\
& +C_{15} C_{\nabla}^{2} \sin \left(\lambda F_{n}^{e}\right)+C_{16} \sin \left(\lambda F_{n}^{e}\right) \frac{1}{F_{n}}+C_{17} C_{\nabla}^{2} \exp \left(\frac{a}{F_{n}^{2}}\right)+C_{18} C_{\nabla}^{2} \exp \left(-\frac{w}{B}\right) \\
& +C_{19} \cos \left(\lambda F_{n}^{e}\right) \exp \left(-\frac{w}{B}\right) \frac{T_{A P}}{T_{X}}+C_{20}\left[\exp \left(-\frac{w}{B}\right)\right]^{2}
\end{aligned}
$$

\section{APPENDIX IV}

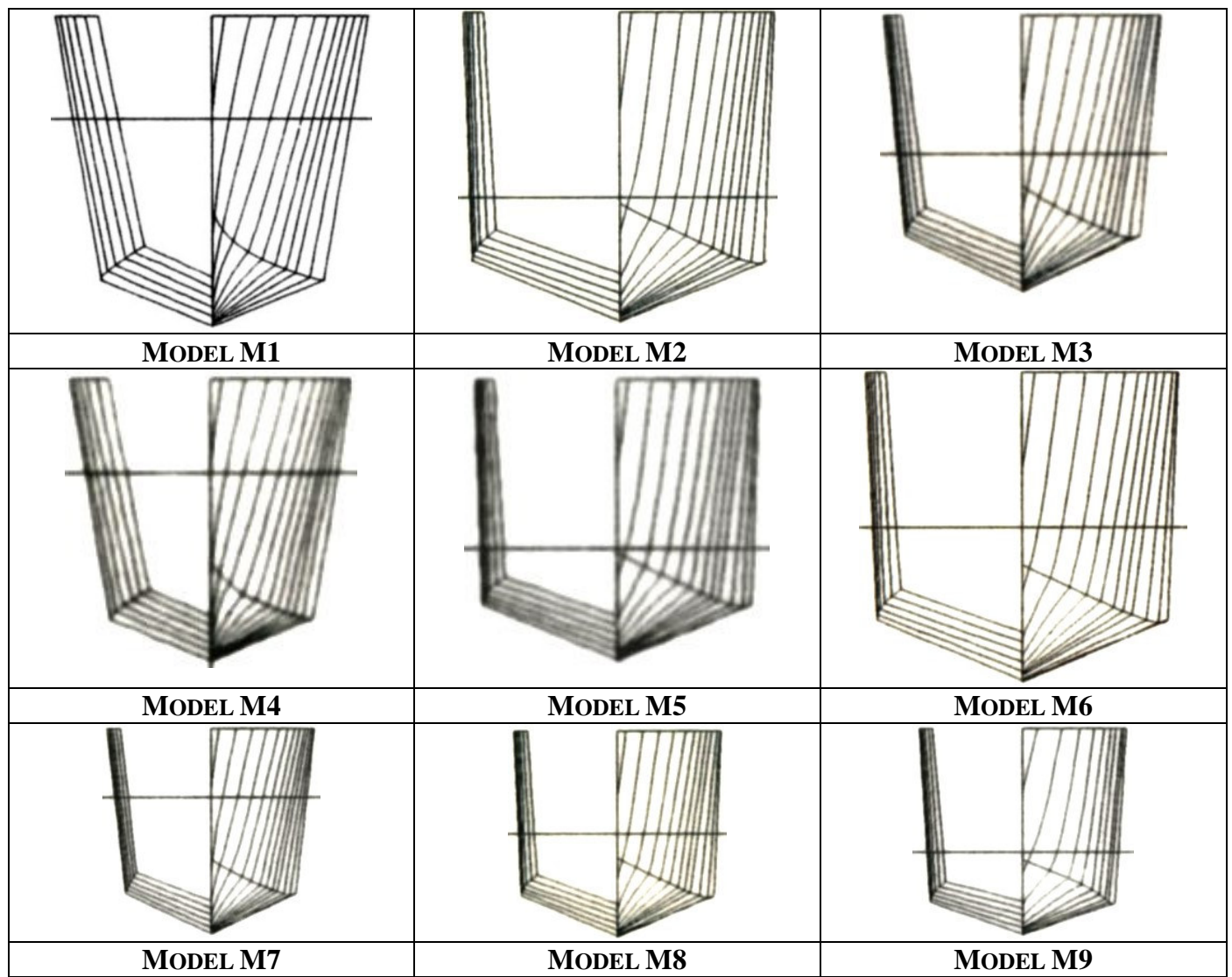




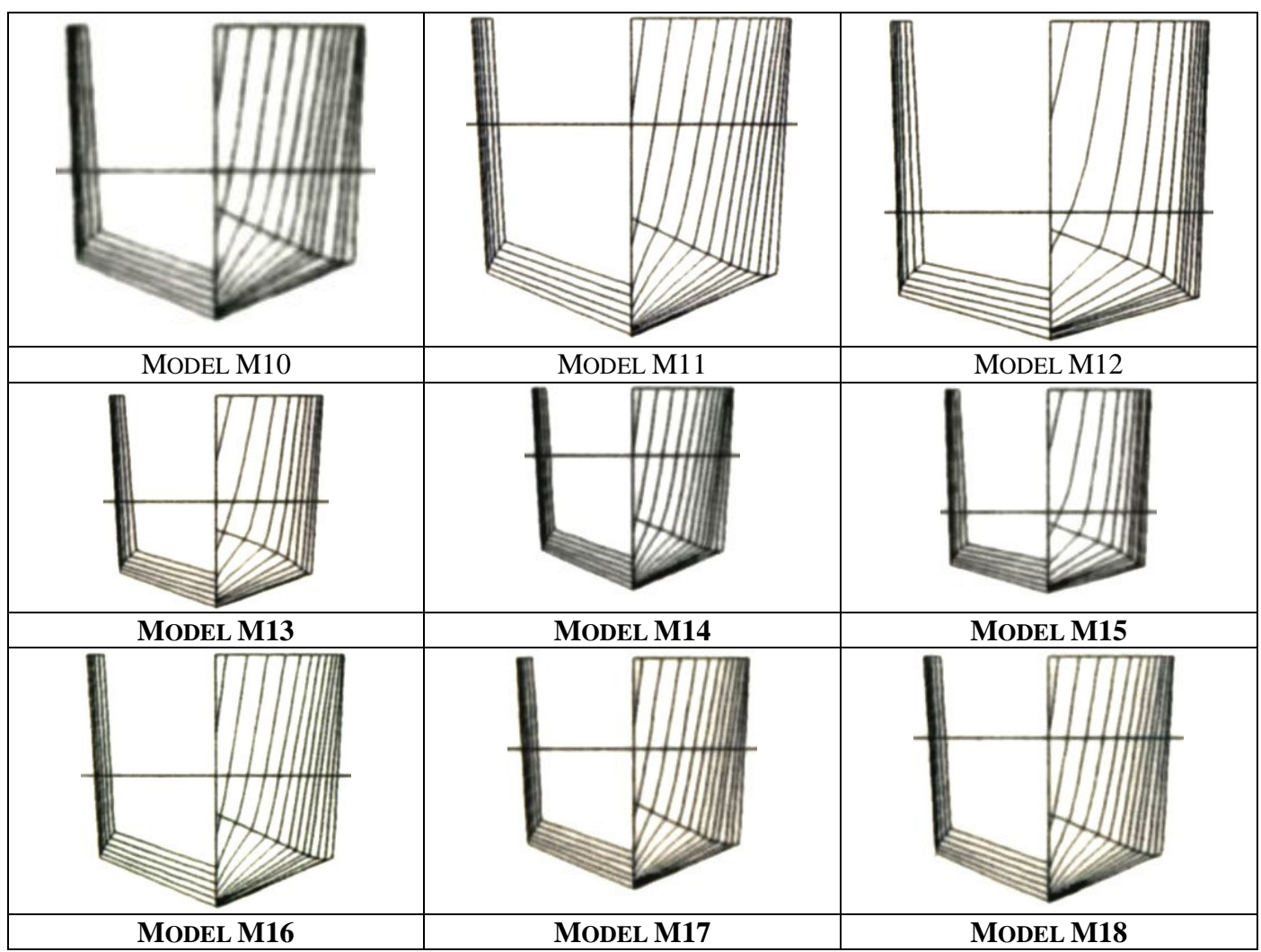

\section{APPENDIX V}

Some of the details of the calculating the demi-hull and catamaran resistance (Schwetz and Sahoo (2002)) are reproduced below. The wave resistance coefficient for a demi-hull can be predicted from equation (16), whose validity range is shown in Table 18, using the constants $C_{1}$ to $C_{4}$ from Table 19.

$C_{W}=C_{1}\left(L / \nabla^{1 / 3}\right)^{C_{2}}(L C B / L C F)^{C_{3}} C_{B} C_{4}$

Table 18: Range of Parameters for Equation 18

\begin{tabular}{|l|c|c|c|c|}
\hline Geometric Parameters & $\mathbf{L} / \boldsymbol{\nabla}^{\mathbf{1 / 3}}$ & $\mathbf{L C B} / \mathbf{L C F}$ & $\mathbf{C}_{\mathbf{B}}$ & $\mathbf{F}_{\mathbf{n}}$ \\
\hline Range of Application & 9.2 to 9.6 & 0.97 to 1.2 & 0.46 to 0.66 & 0.4 to 1.4 \\
\hline
\end{tabular}

Table 19: Coefficients for Equation 18

\begin{tabular}{|c|c|c|c|c|c|}
\hline $\mathbf{F}_{\mathbf{n}}$ & $\mathbf{C}_{\mathbf{1}}$ & $\mathbf{C}_{\mathbf{2}}$ & $\mathbf{C}_{\mathbf{3}}$ & $\mathbf{C}_{\mathbf{4}}$ & $\mathbf{R}^{\mathbf{2}}$ \\
\hline 0.4 & $1.54 \mathrm{E}+02$ & -5.058 & -0.305 & 0.000 & 0.96 \\
\hline 0.5 & $3.00 \mathrm{E}+02$ & -5.519 & -0.466 & -0.1339 & 0.98 \\
\hline 0.6 & $3.61 \mathrm{E}+02$ & -5.715 & -0.488 & -0.1154 & 0.99 \\
\hline 0.7 & $6.87 \mathrm{E}+02$ & -6.113 & -0.591 & -0.108 & 0.99 \\
\hline 0.8 & $1.81 \mathrm{E}+03$ & -6.637 & -0.648 & -0.0981 & 0.99 \\
\hline 0.9 & $4.83 \mathrm{E}+03$ & -7.155 & -0.775 & -0.0933 & 0.99 \\
\hline 1 & $2.99 \mathrm{E}+04$ & -8.064 & -0.982 & -0.1907 & 0.99 \\
\hline 1.1 & $1.97 \mathrm{E}+05$ & -8.995 & -1.191 & -0.292 & 0.99 \\
\hline 1.2 & $1.39 \mathrm{E}+06$ & -9.932 & -1.309 & -0.3178 & 0.99 \\
\hline 1.3 & $5.03 \mathrm{E}+06$ & -10.551 & -1.392 & -0.2913 & 0.99 \\
\hline 1.4 & $5.50 \mathrm{E}+07$ & -11.69 & -1.543 & -0.3903 & 0.98 \\
\hline
\end{tabular}


The wave resistance coefficient for a catamaran can be predicted from equation (17), using the constants $\mathrm{C}_{1}$ to $\mathrm{C}_{7}$ from Table 20 .

$$
C_{w}=C_{1}\left(L / \nabla^{1 / 3}\right)^{C_{2}}(s / L)^{C_{3}}(L C B / L C F)^{C_{4}} i_{E} C_{5}(B / T)^{C_{6}} C_{B}^{C_{7}}
$$

Table 20: Coefficients For Equation 19

\begin{tabular}{|c|c|c|c|c|c|c|c|c|}
\hline $\mathbf{F}_{\mathbf{n}}$ & $\mathbf{C}_{\mathbf{1}}$ & $\mathbf{C}_{\mathbf{2}}$ & $\mathbf{C}_{\mathbf{3}}$ & $\mathbf{C}_{\mathbf{4}}$ & $\mathbf{C}_{\mathbf{5}}$ & $\mathbf{C}_{\mathbf{6}}$ & $\mathbf{C}_{\mathbf{7}}$ & $\mathbf{R}^{\mathbf{2}}$ \\
\hline 0.5 & $2.151 \mathrm{E}+07$ & -12.180 & -0.195 & -0.042 & 0.018 & 2.818 & -3.398 & 0.95 \\
\hline 0.6 & $8.509 \mathrm{E}+03$ & -8.207 & -0.235 & 0.000 & 0.000 & 1.942 & -2.035 & 0.97 \\
\hline 0.7 & $2.194 \mathrm{E}+04$ & -8.840 & -0.180 & -0.073 & 0.027 & 1.992 & -2.215 & 0.92 \\
\hline 0.8 & $5.508 \mathrm{E}+04$ & -9.388 & -0.106 & -0.182 & 0.042 & 2.012 & -2.327 & 0.92 \\
\hline 0.9 & $1.488 \mathrm{E}+05$ & -9.938 & -0.046 & -0.285 & 0.050 & 2.029 & -2.399 & 0.96 \\
\hline 1.0 & $1.303 \mathrm{E}+04$ & -8.590 & -0.016 & -0.422 & 0.026 & 1.583 & -1.757 & 0.98 \\
\hline 1.1 & $5.438 \mathrm{E}+03$ & -8.002 & 0.023 & -0.403 & -0.012 & 1.303 & -1.264 & 0.96 \\
\hline 1.2 & $8.261 \mathrm{E}+06$ & -12.005 & 0.015 & -0.164 & 0.020 & 2.302 & -2.473 & 0.97 \\
\hline 1.3 & $1.440 \mathrm{E}+10$ & -16.090 & 0.004 & 0.072 & 0.102 & 3.230 & -3.690 & 0.99 \\
\hline 1.4 & $1.965 \mathrm{E}+12$ & -18.571 & 0.003 & 0.348 & 0.116 & 3.649 & -4.052 & 0.99 \\
\hline
\end{tabular}

The generalized wave resistance coefficient for a demi-hull can be predicted from equation (18), whose validity range is shown in Table 21, using the constants $C_{1}$ to $C_{5}$ from Table 22.

$$
C_{w}=C_{1}\left(L / \nabla^{1 / 3}\right)^{C_{2}}(L C B / L C F)^{C_{3}}(B / T)^{C_{4}} C_{B}^{C_{5}}
$$

Table 21: Range of Parameters for Equations 18

\begin{tabular}{|l|c|c|c|c|c|}
\hline Geometric Parameters & $\mathbf{L} / \nabla^{\mathbf{1 / 3}}$ & $\mathbf{L C B} / \mathbf{L C F}$ & $\mathbf{B} / \mathbf{T}$ & $\mathbf{C}_{\mathbf{B}}$ & $\mathbf{F}_{\mathbf{n}}$ \\
\hline Range of Application & 6.3 to 9.6 & 0.92 to 1.2 & 1.47 to 2.3 & 0.46 to 0.68 & 0.4 to 1.4 \\
\hline
\end{tabular}

Table 22: Coefficients for Equation 18

\begin{tabular}{|c|c|c|c|c|c|c|}
\hline $\mathbf{F}_{\mathbf{n}}$ & $\mathbf{C}_{\mathbf{1}}$ & $\mathbf{C}_{\mathbf{2}}$ & $\mathbf{C}_{\mathbf{3}}$ & $\mathbf{C}_{\mathbf{4}}$ & $\mathbf{C}_{\mathbf{5}}$ & $\mathbf{R}^{\mathbf{2}}$ \\
\hline 0.5 & 0.30 & -1.2168 & -2.2795 & -2.5075 & 1.4337 & 0.96 \\
\hline 0.6 & 0.41 & -1.4599 & -1.9655 & -2.4304 & 1.5754 & 0.98 \\
\hline 0.7 & 0.68 & -2.1421 & -1.6111 & -1.6934 & 1.1637 & 0.99 \\
\hline 0.8 & 0.78 & -2.4272 & -1.5211 & -1.4089 & 1.0263 & 0.99 \\
\hline 0.9 & 0.87 & -2.6947 & -1.5148 & -1.1202 & 0.8731 & 0.98 \\
\hline 1.0 & 0.93 & -2.9213 & -1.5536 & -0.8650 & 0.7080 & 0.98 \\
\hline 1.1 & 1.00 & -3.1409 & -1.5821 & -0.6142 & 0.5526 & 0.98 \\
\hline 1.2 & 1.16 & -3.3948 & -1.5593 & -0.3228 & 0.4110 & 0.97 \\
\hline 1.3 & 1.38 & -3.6728 & -1.5278 & 0.000 & 0.2509 & 0.97 \\
\hline 1.4 & 1.65 & -3.9787 & -1.5547 & 0.35234 & 0.000 & 0.97 \\
\hline
\end{tabular}

The generalized wave resistance coefficient for a catamaran can be predicted from equation (19), using the constants $\mathrm{C}_{1}$ to $\mathrm{C}_{7}$ from Table 23 .

$$
C_{w}=C_{1}\left(L / \nabla^{1 / 3}\right)^{C_{2}}(s / L)^{C_{3}}(L C B / L C F)^{C_{4}} i_{E}^{C_{5}} \cdot C_{B}^{C_{6}}(B / T)^{C_{7}}
$$


Table 23: Coefficients for Equation 19

\begin{tabular}{|c|c|c|c|c|c|c|c|c|}
\hline $\mathbf{F}_{\mathbf{n}}$ & $\mathbf{C}_{\mathbf{1}}$ & $\mathbf{C}_{\mathbf{2}}$ & $\mathbf{C}_{\mathbf{3}}$ & $\mathbf{C}_{\mathbf{4}}$ & $\mathbf{C}_{\mathbf{5}}$ & $\mathbf{C}_{\mathbf{6}}$ & $\mathbf{C}_{\mathbf{7}}$ & $\mathbf{R}^{2}$ \\
\hline 0.5 & 1.501 & -2.632 & -0.201 & -1.554 & -0.132 & 1.070 & -1.460 & 0.99 \\
\hline 0.6 & 1.122 & -2.817 & -0.305 & -1.265 & -0.090 & 0.971 & -1.259 & 0.99 \\
\hline 0.7 & 0.613 & -2.734 & -0.278 & -1.290 & -0.064 & 0.988 & -1.317 & 0.99 \\
\hline 0.8 & 0.282 & -2.652 & -0.195 & -1.472 & -0.052 & 0.996 & -1.395 & 0.99 \\
\hline 0.9 & 0.209 & -2.668 & -0.111 & -1.645 & -0.048 & 1.002 & -1.422 & 0.99 \\
\hline 1.0 & 0.356 & -2.820 & -0.056 & -1.756 & -0.052 & 0.964 & -1.339 & 0.99 \\
\hline 1.1 & 0.878 & -3.129 & 0.000 & -1.640 & -0.068 & 0.974 & -1.171 & 0.99 \\
\hline 1.2 & 1.455 & -3.476 & 0.000 & -1.365 & -0.092 & 1.051 & -0.962 & 0.99 \\
\hline 1.3 & 1.594 & -3.615 & 0.000 & -1.105 & -0.069 & 1.179 & -0.873 & 0.99 \\
\hline 1.4 & 2.337 & -4.056 & -0.032 & -0.658 & -0.072 & 1.338 & -0.614 & 0.99 \\
\hline
\end{tabular}

\section{APPENDIX VI}

$$
\begin{aligned}
& C_{\text {Wdemi } i}=e^{C_{1}}\left(\frac{L}{B}\right)^{C_{2}}\left(C_{B}\right)^{C_{3}}\left(\frac{L}{\nabla^{1 / 3}}\right)^{C_{4}}\left(i_{E}\right)^{C_{5}}(\beta)^{C_{6}} \\
& C_{\text {Wcat }}=e^{C_{1}}\left(\frac{L}{B}\right)^{C_{2}}\left(\frac{B}{T}\right)^{C_{3}}\left(C_{B}\right)^{C_{4}}\left(\frac{L}{\nabla^{1 / 3}}\right)^{C_{5}}\left(i_{E}\right)^{C_{6}}(\beta)^{C_{7}}\left(\frac{s}{L}\right)^{C_{8}}
\end{aligned}
$$

Table 24: Regression Coefficients and $\mathbf{R}^{2}$ for demi-hull Configuration for Equation 20

\begin{tabular}{|c|c|c|c|c|c|c|c|}
\hline $\mathbf{F n}$ & $\mathbf{C}_{\mathbf{1}}$ & $\mathbf{C}_{\mathbf{2}}$ & $\mathbf{C}_{\mathbf{3}}$ & $\mathbf{C}_{\mathbf{4}}$ & $\mathbf{C}_{\mathbf{5}}$ & $\mathbf{C}_{\mathbf{6}}$ & $\mathbf{R}^{\mathbf{2}}$ \\
\hline 0.2 & 3.001 & -0.159 & 0.515 & -3.666 & -0.194 & 0.000 & 0.967 \\
\hline 0.3 & 1.221 & 0.000 & 0.815 & -3.445 & 0.218 & 0.000 & 0.985 \\
\hline 0.4 & 3.180 & -0.702 & 0.377 & -3.114 & -0.390 & 0.000 & 1.000 \\
\hline 0.5 & 2.519 & 0.396 & -0.775 & -4.175 & 0.000 & -0.410 & 0.999 \\
\hline 0.6 & 2.031 & -0.239 & 0.000 & -3.402 & -0.138 & -0.091 & 0.999 \\
\hline 0.7 & 1.130 & -0.220 & 0.000 & -3.221 & -0.043 & -0.081 & 0.999 \\
\hline 0.8 & 0.600 & -0.272 & 0.000 & -3.079 & 0.000 & -0.063 & 0.999 \\
\hline 0.9 & -0.216 & 0.000 & -0.228 & -3.158 & 0.173 & -0.178 & 0.999 \\
\hline 1.0 & -1.086 & 0.000 & -0.396 & -2.965 & 0.300 & -0.203 & 0.998 \\
\hline
\end{tabular}

Table 25: Regression Coefficients and $\mathbf{R}^{2}$ for Catamaran Configuration for Equation 21

\begin{tabular}{|c|c|c|c|c|c|c|c|c|c|}
\hline $\mathbf{F n}$ & $\mathbf{C}_{\mathbf{1}}$ & $\mathbf{C}_{\mathbf{2}}$ & $\mathbf{C}_{\mathbf{3}}$ & $\mathbf{C}_{\mathbf{4}}$ & $\mathbf{C}_{\mathbf{5}}$ & $\mathbf{C}_{\mathbf{6}}$ & $\mathbf{C}_{\mathbf{7}}$ & $\mathbf{C}_{\mathbf{8}}$ & $\mathbf{R}^{2}$ \\
\hline 0.2 & 2.571 & 0.436 & 0.000 & 0.000 & -4.124 & -0.039 & -0.199 & 0.037 & 0.995 \\
\hline 0.3 & 0.585 & 0.000 & 0.000 & 0.945 & -3.282 & 0.246 & 0.087 & -0.089 & 0.989 \\
\hline 0.4 & 3.324 & 0.000 & -0.471 & -0.963 & -3.523 & 0.000 & -0.688 & -0.035 & 0.984 \\
\hline 0.5 & 2.439 & 0.379 & 0.000 & -0.600 & -4.262 & 0.000 & -0.337 & -0.368 & 0.999 \\
\hline 0.6 & 1.809 & -0.110 & 0.000 & 0.000 & -3.625 & -0.061 & -0.095 & -0.314 & 0.997 \\
\hline 0.7 & 1.055 & 0.000 & 0.082 & -0.025 & -3.617 & 0.000 & -0.064 & -0.181 & 0.997 \\
\hline 0.8 & 0.603 & 0.222 & 0.266 & 0.000 & -3.869 & 0.000 & 0.000 & -0.069 & 0.998 \\
\hline 0.9 & -0.466 & 0.049 & 0.162 & 0.000 & -3.322 & 0.128 & 0.000 & -0.006 & 0.999 \\
\hline 1.0 & -1.221 & 0.000 & 0.117 & 0.000 & -3.046 & 0.264 & 0.000 & 0.075 & 0.995 \\
\hline
\end{tabular}

